\title{
RESOCIALIZACIÓN Y ENCUESTAS DE CALIDAD DE VIDA PENITENCIARIA
}

\author{
Jesús Barquín Sanz \\ Catedrático de la Universidad de Granada \\ Miguel Ángel Cano Paños \\ Profesor titular de la Universidad de Granada \\ María Ángeles Calvo Alba \\ Investigadora de la Universidad de Granada
}

Sumario: 1. Introducción. 2. Caracterización de los centros penitenciarios encuestados. 3. Hipótesis de partida. 4. Metodología. 4.1. Tests estadísticos. 5. Resultados. 5.1. Perfil de la población penitenciaria. 5.2. Percepción de las relaciones entre reclusos y personal del centro. 5.2.1. Análisis de chi cuadrado y Eta. 5.3. Percepción de las relaciones de los internos entre sí. 5.3.1. Análisis de chi cuadrado y Eta. 5.4. Percepción del ambiente en prisión y sus repercusiones en la resocialización. 5.4.1. Análisis de chi cuadrado y Eta. 5.5. Índices de percepción de las relaciones entre internos y funcionarios, internos entre sí, y el ambiente en prisión y su repercusión en la resocialización. 5.5.1. Análisis de chi cuadrado y Eta. 6 . Conclusiones. 7. Referencias.

Resumen: En el presente artículo se presentan y analizan los resultados estadísticos obtenidos de 454 encuestas de autoinforme dirigidas a evaluar la calidad de vida en prisión que han sido completadas por algo más del diez por ciento de la población penitenciaria de cinco centros del sur de España, cuatro de ellas en Andalucía oriental, más el centro penitenciario de Melilla. Se trata de una investigación realizada a partir de una versión independiente de la encuesta original desarrollada por Alison Liebling Measuring the Quality of Prison Life (MQPL).

El principal objetivo general es contribuir a profundizar en el conocimiento de la realidad de las prisiones españolas. En términos más específicos, verificar si se confirma, o no, el fundamento constitucional con el que se sigue concibiendo la pena de prisión en España: la reedu- 
cación y reinserción social del condenado (artículo 25.2 CE). Para ello se analizan las respuestas a una serie de preguntas que se enmarcan en tres variables o dimensiones: (1) la relación de los internos con el personal de prisión; (2) la relación de los reclusos entre sí; (3) la eficacia o no del tratamiento penitenciario de cara a su reincorporación a la sociedad.

El análisis permite no sólo vislumbrar diferencias en cuanto al régimen de vida de los centros penitenciarios analizados sino, además, evaluar la validez de la hipótesis de partida, a saber, la vigencia actual de lo establecido en el mencionado precepto constitucional.

Palabras clave: prisión, reclusos, sistema penitenciario, calidad de vida, resocialización, reinserción, reeducación, MQPL.

Abstract: This paper presents and analyzes statistical results obtained from 454 self-report surveys aimed at evaluating the quality of prison life of inmates. These have been completed by over ten percent of the prison population of five prisons in the south of the Spain, four of them in eastern Andalusia, plus the penitentiary center of Melilla. The research is based on an independent version of the the original survey developed by Alison Liebling, Measuring the Quality of Prison Life (MQPL).

The main general objective of this paper is to contribute to deepening the knowledge of the reality of Spanish prisons. In more specific terms, to inquire into the validity of the hypothesis on which prison sentences are still formally based in Spain: re-education and social reintegration of the convicted person (article 25.2 of the Spanish Constitution). For this purpose, we have analyzed the current state of prison 'morals' from the answers of the surveyed prisoners to a questionnaire that includes, among others, some questions connected with the following three issues: (1) their relationship with prison staff; (2) their relationship with other inmates; (3) the effectiveness or ineffectiveness of prison treatment in terms of their reintegration into society.

The research will allow not only to detect possible differences in the prison life of the five penitentiaries analyzed, but also to confirm or not the initial hypothesis raised, namely, the current validity of what is established in the aforementioned artículo 25.2 of the Spanish Constitution.

Keywords: prison, inmates, penitentiary system, quality of life, reeducation, social rehabilitation, MQPL. 


\section{Introducción ${ }^{1}$}

El sistema penitenciario no ha sido a lo largo de las últimas décadas el área de mayor interés para los criminólogos españoles. Éstos en cambio han tendido a ocuparse fundamentalmente del estudio de las causas de la delincuencia, la persona del delincuente y, en menor medida, la víctima de la acción delictiva. A pesar de ello, en los últimos años han ido apareciendo distintos estudios de naturaleza cuantitativa y cualitativa sobre el contexto penitenciario cuyo objeto ha sido analizar tanto la situación de las prisiones españolas como - sólo en contadas ocasionesla denominada "calidad de vida penitenciaria» ${ }^{2}$.

Uno de los primeros estudios empíricos realizados con la población reclusa en España fue el llevado a cabo por CABRERA CABRERA y Ríos MARTín. Estos autores elaboraron un cuestionario que fue cumplimentado por un total de 1.011 personas que se encontraban en prisión durante el año 1997 (CABRERA y Ríos, 1998). El cuestionario no fue repartido directamente por los investigadores en los correspondientes centros penitenciarios, sino que, tras la preceptiva aprobación de la Secretaría General de Instituciones Penitenciarias (SGIP), fue enviado a los reclusos a través del correo ordinario y repartido por la dirección de cada centro. Como resultado de la encuesta se pudo obtener una radiografía interior de la vida en prisión que transmitía tanto a la sociedad en general como a los profesionales implicados en el contexto penitenciario una visión de primera mano a partir del relato de los propios presos. Este trabajo constituyó la base de un trabajo empírico posterior al que se hará referencia más adelante.

Desde una perspectiva eminentemente cuantitativa merece ser destacado también un estudio llevado a cabo por BENítez JimÉnEZ en el que analiza la evolución de la población reclusa en España en el período comprendido entre los años 1998 y 2006 (BENítez, 2006). El objetivo del estudio era conocer, a través de la explotación de datos estadísticos publicados por instancias oficiales, el volumen y características demográficas de la población penitenciaria en España, tanto a nivel estatal como con respecto a las distintas Comunidades Autónomas. Los datos publicados por el Ministerio del Interior mostraban una población reclusa en España que creció de manera continuada a partir del año 1999, superando con creces la cifra de 60.000 internos en el año 2006. La conclusión a la que

1 El presente artículo está basado en el desarrollo completo del trabajo de campo que dio lugar a una publicación anterior en la que se exponían los resultados provisionales relativos a los dos centros penitenciarios que fueron encuestados en primer y segundo lugar (BARQUín SanZ, J., Cano PaÑos M.Á. y Calvo AlBa, M.Á., 2016). En buena medida, los resultados provisionales entonces publicados se han visto corroborados ulteriormente por los resultados acumulados de los cinco centros que constituían el ámbito total de la investigación.

2 A continuación en el texto se hace un sumario repaso de la literatura al respecto. Para una revisión extensa y en profundidad, es de gran interés el trabajo de MARTí BARRACHINA (2017). 
llega la autora del trabajo es que, en la época en la que se realizó el estudio, España destacaba tanto por su alta tasa de encarcelamiento - si la misma se compara con otros países europeos- como por la densidad de ocupación de sus prisiones, que el aumento de la población reclusa sería una constante en años futuros.

Este pronóstico se cumplió, pero sólo durante un tiempo, ya que la población penitenciaria en España comenzó a disminuir significativamente desde el año 2010, cuando se alcanzó una cifra máxima de 76.951 internos, hasta 2017, con un pequeño repunte seguido de consolidación en torno a los 59.000 reclusos a lo largo de 2018. De hecho, el máximo en cifras de cierre de ejercicio anual se alcanzó en diciembre de 2009, con un total de 76.079 personas privadas de libertad. Desde entonces, la población penitenciaria estuvo continuamente disminuyendo en cómputo anual hasta las últimas de cierre de año que han sido publicadas, correspondientes a diciembre de 2017 (véase Gráfico 1).

\section{Gráfico 1. Evolución de la población penitenciaria en España (2000-2017)}

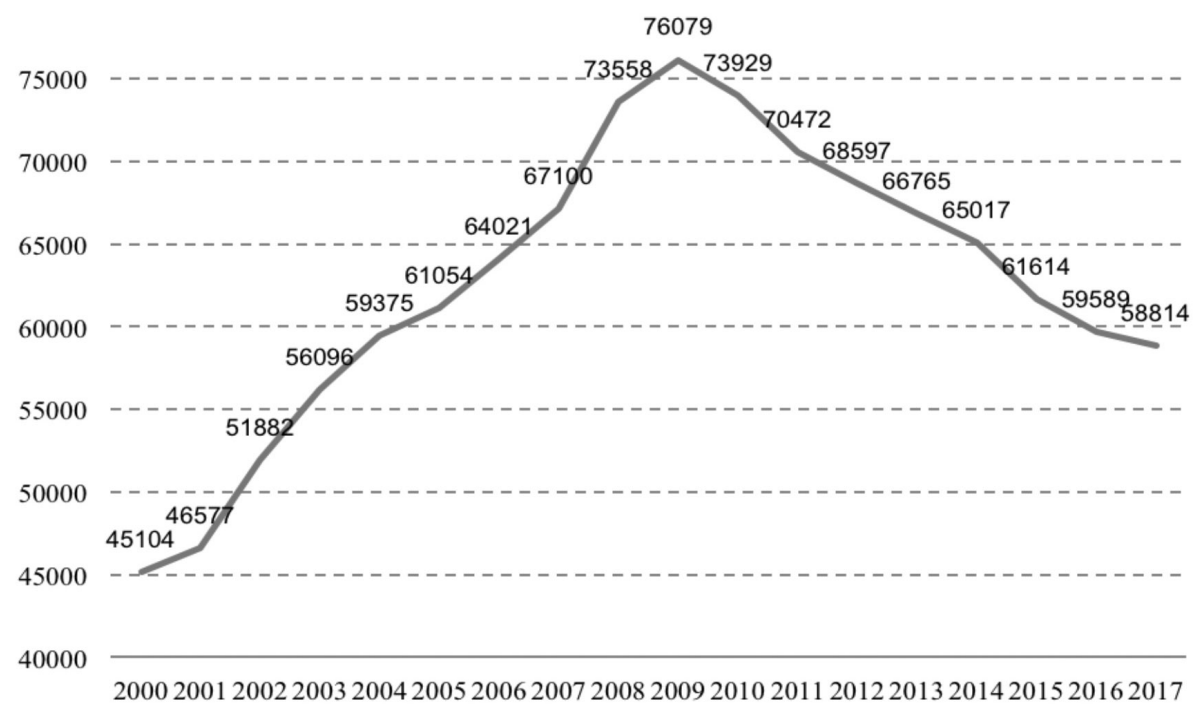

Fuente: Elaboración propia, basada en datos de www.institucionpenitenciaria.es y www.ine.es.

Las estadísticas oficiales arrojan que en diciembre de 2017 la población penitenciaria total en España era de 58.814 reclusos $^{3}$, siendo así

\footnotetext{
3 Véase http://www.institucionpenitenciaria.es/web/portal/documentos/estadisticas.html

Durante 2018 las cifras se han ido consolidando ligeramente por encima de ese número, con un máximo de 59.694 presos en junio de 2018 y un mínimo de 59.070 en septiembre del
} 
que en enero de 2018 (fecha del último censo oficial de población) la población total española era de casi 46,7 millones de personas. De ello resulta una tasa de encarcelamiento de 126 reclusos por cada 100.000 habitantes, más alta que la de otros países comparables del centro y el norte de Europa (exceptuando el Reino Unido), pero notablemente menor que las de la mayor parte de los países del este de Europa (véase Gráfico 2). A efectos únicamente comparativos, la tasa equivalente en los Estados Unidos en la misma época era de 655 reclusos por 100.000 habitantes.

\section{Gráfico 2. Tasa de encarcelamiento (por 100.000 habitantes)}

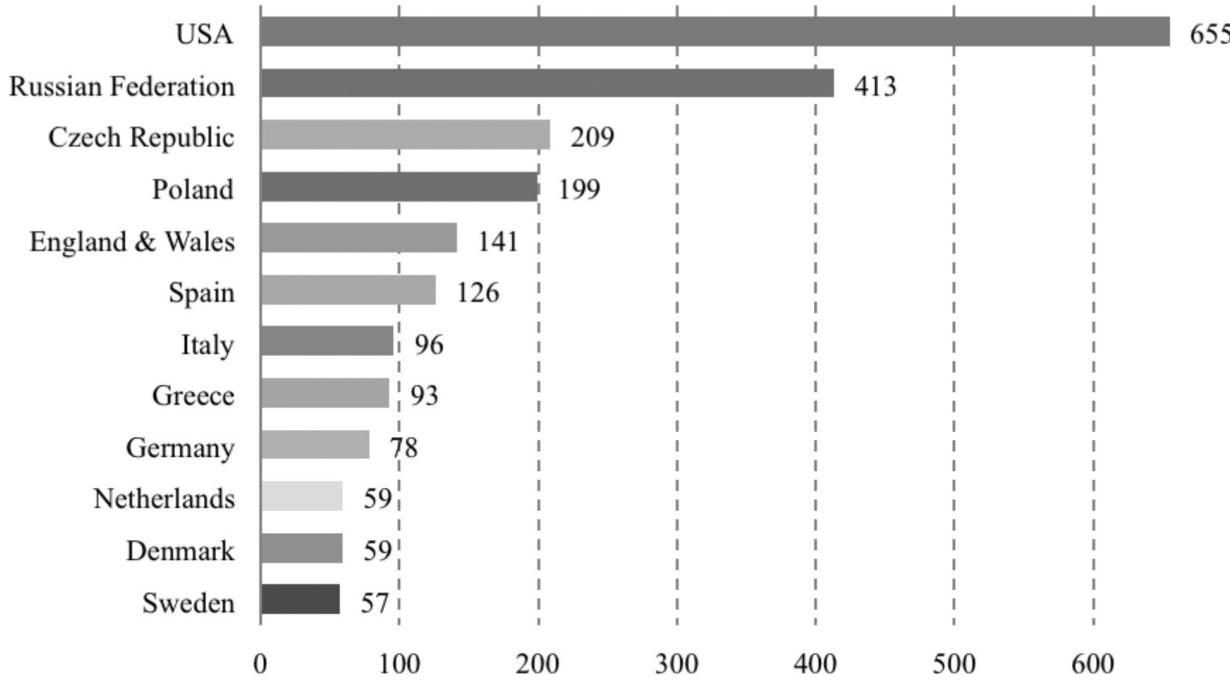

Fuente: Elaboración propia, basada en los últimos datos disponibles en World Prison Brief, Institute for Criminal Policy Research (www.prisonstudies.org).

Quizá uno de los estudios empíricos más importantes llevados a cabo en España en el contexto penitenciario es el realizado por GALLEGo DíAZ, Cabrera Cabrera, Ríos Martín y Segovia Bernabé (Gallego et al., 2010). Se trata de un desarrollo del trabajo publicado una docena de años antes por dos de estos autores que se ha mencionado supra (CABRERA y Ríos, 1998). La metodología utilizada en el nuevo estudio combinaba la explo-

mismo año. Las últimas cifras publicadas en el momento de escribir esta nota son las de la semana número 47 en noviembre de 2018: 59.297 internos. En algunos períodos de años anteriores se había verificado un incremento coyuntural que no impidió la tendencia general a un descenso a través de los datos finales de diciembre de cada año. En principio, parece no obstante improbable $a$ priori que este fenómeno termine produciéndose de nuevo en 2018. 
tación estadística de unos cuestionarios que fueron contestados por un total de 1.668 reclusos que se encontraban cumpliendo condena en 46 centros penitenciarios, junto con el análisis de los textos recogidos en las preguntas abiertas formuladas a los propios presos, así como con la reflexión a partir del análisis del discurso expresado a través de las entrevistas focalizadas que se realizaron en los mismos centros penitenciarios a directores, responsables de tratamiento, psicólogos, juristas criminólogos y trabajadores sociales (Gallego, Ríos, CABRERa y SEgovia, 2010). Conviene señalar que tampoco en este caso la encuesta se realizó de forma presencial, sino que los cuestionarios fueron remitidos por correo a un total de 66 establecimientos penitenciarios, con instrucciones a los centros para que, al llegar el paquete con los cuestionarios, éstos se distribuyesen de forma aleatoria y respetando estrictamente una cuota que previamente habían establecido los autores del estudio para cada concreto centro penitenciario en función del número de internos, su sexo y situación penitenciaria. ${ }^{4}$ El cuestionario elaborado por los autores del estudio estaba integrado fundamentalmente por preguntas de carácter socio-demográfico que hacían referencia a aspectos como el sexo, el estado civil, la edad, el trabajo, la nacionalidad, el nivel de estudios o el origen familiar. Además, contenía preguntas sobre aspectos del tratamiento penitenciario, de la vida en prisión e incluso sobre sentimientos de los propios internos en relación con las víctimas. Se trata, por tanto, fundamentalmente de un estudio etnográfico y sociológico sobre la población reclusa en España, lo que, tal y como señalan sus propios autores, representó en su momento la muestra más numerosa jamás alcanzada en los estudios penitenciarios que hasta la fecha se habían realizado en este país.

Tiene asimismo particular interés el estudio publicado en 2015 por CUTIÑO RAYA sobre la realidad del tratamiento en las prisiones españolas. En él se analizan los distintos programas de tratamiento - los generales y los más específicos destinados a determinados tipos de delincuentestanto desde una perspectiva teórica como en atención a su aplicación práctica en la realidad penitenciaria, con la conclusión de que no se ejecutan en las condiciones y con la frecuencia necesarias como para lograr los objetivos fundamentales para los que fueron creados: la reeducación y reinserción social de las personas privadas de libertad (CuTiÑo, 2015). El autor señala con datos estadísticos que los programas de tratamiento sólo llegan a una minoría de la población penitenciaria, que faltan recursos materiales y personales, y que la mayoría están dedicados al control y la seguridad, lo que en su opinión provoca un escaso contacto de los equipos técnicos con la población reclusa. Argumenta asimismo que los programas que se ponen en práctica son escasos y poco orientados hacia

4 Junto a cada cuestionario se enviaba una carta de presentación y un sobre autofranqueado en el que los internos debían introducir el cuestionario una vez cumplimentado de forma que pudieran remitirlo directa y personalmente a los autores del estudio. 
una recuperación de la persona en la sociedad normalizada del exterior; a juicio del autor el tratamiento penitenciario, contra lo establecido en la legislación, que lo considera el centro de la actividad penitenciaria, constituye en la práctica el principal recurso para garantizar la disciplina y la vigilancia en las prisiones.

Por último mencionaremos un reciente estudio criminológico publicado en España sobre la vida en prisión por Rodríguez MENÉs, LARRAURI PIJOAN y GÜERRI FERRÁndez (2018). Su investigación se basa en una metodología similar a la empleada por nosotros para la realización del presente trabajo, puesto que ambos grupos, respectivamente basados en la Universitat Pompeu Fabra y en la Universidad de Granada, hemos trabajado coordinadamente y con frecuente contacto académico. La base de su estudio es una encuesta distribuida a una muestra de 500 reclusos en cuatro prisiones masculinas de la provincia de Barcelona. Los resultados evidencian que las condiciones de vida difieren significativamente entre las prisiones. Los autores exponen que estas diferencias se deben no tanto a la trayectoria delictiva de los reclusos y su clasificación penitenciaria, sino más bien a la organización de cada centro y a las relaciones interpersonales establecidas en cada uno de ellos (RODRÍGUEZ, LARRAURI Y GÜERRI, 2018).

Este tipo de trabajos, al igual que el que ahora presentamos, son útiles para contribuir a rellenar el relativo vacío que hay en España en cuanto al estudio de la vida penitenciaria desde una perspectiva criminológica. Hay un número de publicaciones sobre el crecimiento de la tasa de encarcelamiento (así, DíEz-RIPOllés, 2006; CiD, 2008; BECERRA, 2012) así como, desde 2010, sobre su disminución (BRANDÁRIZ, 2015; DÜNKEL, 2017). Existen también los estudios generales ya mencionados sobre las condiciones de vida en las prisiones españolas desde la perspectiva de los reclusos a través de cuestionarios que no discriminan los resultados de diferentes centros (CABRERA y Ríos, 1998; GALlEgo et al., 2010), con la excepción de la reseñada investigación de RODRÍGUEZ, LARRAURI Y GÜERRI (2018).

En cambio, en otros países se ha publicado un número de trabajos que demuestran la existencia de diferentes tipos de prisiones que acarrean consecuencias particularmente negativas para los reclusos (DiIUlio, 1987; Sparks y BotTOMS, 1995; LIEBling, 2004; KRUtTSCHNitT y DiRKZWAGER, 2011; BEYENS y BoONE, 2015). El autor pionero en cuanto al estudio de la calidad de vida en las prisiones fue Rudolf Moos, quien en la década de 1960 midió el ambiente social de una prisión con objeto de discernir su eficacia terapéutica; a estos efectos elaboró un cuestionario que fue distribuido tanto a reclusos como a personal de las prisiones (Moos, 1968).

A pesar de la ola de pesimismo reinante en la sociedad española en general y el legislador penal en particular en lo referente al ideal de la resocialización en el contexto de la pena de prisión, el mandato conte- 
nido en el artículo 25.2 de la Constitución española (CE) sigue, por el momento, plenamente vigente. En virtud de lo allí establecido, «las penas privativas de libertad y las medidas de seguridad estarán orientadas hacia la reeducación y reinserción social y no podrán consistir en trabajos forzados».

A partir de esta previsión constitucional, la calidad de vida penitenciaria está directamente relacionada con dos conceptos que se antojan cruciales de cara a conseguir el objetivo último de la ejecución de la pena de prisión: el régimen y el tratamiento penitenciario. El régimen penitenciario, tal y como señala el artículo 73.1 del Reglamento Penitenciario (RP), está constituido por «el conjunto de normas o medidas que persiguen la consecución de una convivencia ordenada y pacífica que permita alcanzar el ambiente adecuado para el éxito del tratamiento y la retención y custodia de los reclusos». Por su parte, y acudiendo en este caso a lo prescrito en el artículo 59.1 de la Ley Orgánica General Penitenciaria (LOGP), el tratamiento penitenciario consiste «en el conjunto de actividades directamente dirigidas a la consecución de la reeducación y reinserción social de los penados». En este contexto, parece claro que tanto el régimen como el tratamiento penitenciario deben coordinarse y complementarse entre sí, puesto que el buen o mal funcionamiento de uno, de otro, o de ambos, repercute indudablemente en la calidad de vida penitenciaria.

A partir de los postulados teóricos expuestos en los párrafos anteriores, y asumiendo los autores de este trabajo una concepción matizadamente optimista de las funciones inherentes al cumplimiento de la pena de prisión, a la que no se puede pedir más que lo que razonablemente está en disposición de proveer: una ejecución compatible con la dignidad personal y con el potencial de reinserción del recluso, es del mayor interés analizar y conocer el actual contexto penitenciario español. Probablemente el modo más acertado de acceder a este conocimiento no sean los informes oficiales o las experiencias relatadas por funcionarios o profesionales encargados de llevar a la práctica el mandato contenido en los arts. 25.2 CE y 1 LOGP. Por el contrario los protagonistas de este estudio son los propios reclusos, a través de las respuestas dadas de forma anónima a un exhaustivo cuestionario, así como mediante el contacto directo mantenido con los propios autores de este estudio en una serie de visitas a cinco prisiones del este de Andalucía (Almería, Granada, Málaga y Jaén) y de Melilla durante los años 2015, 2016 y 2017.

\section{Caracterización de los centros penitenciarios encuestados}

Los cinco centros penitenciarios visitados están regulados por unas mismas normas y responden a un mismo modelo penitenciario, además 
de estar ubicados en un ámbito geográfico social e históricamente homogéneo que se corresponde a grandes rasgos con el territorio materialmente cubierto durante siglos por la Universidad de Granada antes de que se fundaran las universidades de Málaga (1972), Jaén (1993) y Almería $(1993)^{5}$. Comparten también básicamente los programas de tratamiento, de los cuales los más relevantes son: a) programa de violencia en el ámbito familiar; b) programa de atención a drogodependientes; c) programa de atención integral a enfermos mentales; d) programa de intervención con mujeres.

En cambio difieren, en algunos casos de manera muy acentuada, en cuanto a tamaño y en cuanto a algunas características que están conectadas con el número de reclusos que alberga cada uno.

El número de reclusos en cada prisión y en total en las fechas de las encuestas era el siguiente:

Almería: 763 (714 hombres, 49 mujeres)

Granada: 1416 (1237 hombres, 179 mujeres)

Jaén: 522 (487 hombres, 35 mujeres)

Málaga: 1123 (1008 hombres, 115 mujeres)

Melilla: 257 (248 hombres, 9 mujeres)

TOTAL: 4081 (3694 hombres, 387 mujeres).

La muestra fue de 454 personas (véase infra, Tabla I).

Como se puede observar, el mayor de ellos es el de Granada; y también el más densamente poblado, con más de 1.400 internos cuando su capacidad óptima es de 1.008 internos; es éste un factor que no debe perderse de vista en cuanto a su repercusión en las tres dimensiones estudiadas. Parece razonable asociar sobrepoblación con relaciones más tensas entre internos y personal, de los internos entre sí y con un ambiente menos amable que repercute en la integración de los reclusos. Todo ello, cabe esperar, debe reflejarse en la percepción por los reclusos de su calidad de vida en prisión. Por lo demás, nuestra percepción durante las visitas realizadas es que, quizás por ello, se trataba también del centro en el que se apreciaba una mayor rigidez, con medidas de seguridad estrictas en los movimientos de reclusos. Por ejemplo, en esta prisión no se formaron grupos amplios de internos para realizar las encuestas, sino que se hicieron en pequeños grupos de unas quince personas cada vez, pertenecientes a un par de módulos. En otras pri-

5 La Universidad de Granada está aún presente en la Ciudad Autónoma de Melilla a través del Campus Universitario de Melilla, como por lo demás también tiene presencia equivalente en la Ciudad Autónoma de Ceuta. 
siones en cambio, como Almería, Melilla y Málaga, se formaron grupos amplios de hasta cincuenta personas, con una sensación general de notable mayor relajación en cuanto a los desplazamientos internos de los reclusos desde sus módulos a las aulas en que participaron en la encuesta, y en los movimientos de un módulo a otro. En Jaén hubo una organización mixta a este respecto, con un grupo más amplio de unas treinta personas pertenecientes a los módulos con régimen menos estricto que realizaron la encuesta en la biblioteca del centro, y aparte pequeños grupos que contestaron separadamente en sus propios módulos. Siempre con la presencia de uno o varios investigadores que dábamos las indicaciones y aclaraciones pertinentes, y en ausencia de funcionarios en la sala.

En casi todos los casos los cuestionarios fueron respondidos por los reclusos en presencia de los dos investigadores de la Universidad de Granada que firman en primer lugar este trabajo, con las colaboraciones puntuales de un compañero del Instituto Andaluz Interuniversitario de Criminología de nuestra universidad en los centros de Almería y Melilla ${ }^{6}$, y de dos investigadoras de la Universitat Pompeu Fabra de Barcelona en el Centro Penitenciario de Jaén ${ }^{7}$.

Málaga coincide con Granada en una notable sobrepoblación, con una población penitenciaria media ${ }^{8}$ en las fechas de las visitas de 1.123 personas para una capacidad ideal de 837, así como en que sus instalaciones son relativamente modernas. Sin embargo, en las dos visitas realizadas obtuvimos una impresión de un entorno más relajado, quizás por la ausencia de tensiones sindicales como las que en los últimos años se vienen reportando sobre la prisión de Granada.

Jaén, aunque más pequeña y a primera vista no superpoblada (población real de 522 personas en la fecha de la visita para una capacidad ideal de 571 $)^{9}$, también producía la impresión de un entorno equilibrado, excepto por el hecho de que muchos reclusos se quejaban del excesivo calor en las celdas, incluso por las noches.

Almería (población real de 763 personas, capacidad ideal de 567) parecía un centro bien organizado con una impresión general de interacción relajada de los reclusos entre sí y con los funcionarios, así como una relativa libertad de movimientos dentro de las instalaciones.

6 Agradecemos expresamente su colaboración a LORENZo MoRILlas.

7 Agradecemos expresamente su colaboración a ElENA LARRAURI y a CRISTINA GÜERRI.

8 El número exacto de reclusos fluctúa cada día; se ha indicado la media de las cifras que nos fueron comunicadas.

9 Puede suceder que el número real de reclusos de un determinado centro penitenciario sea inferior al de la capacidad ideal del mismo, y al mismo tiempo se produzca un cierto grado de sobrepoblación por el hecho de que uno o varios módulos estén cerrados por obras de rehabilitación o por otro motivo. Era el caso de este centro penitenciario en la fecha en que se realizaron las encuestas. 
De hecho, pudimos movernos ampliamente dentro del centro penitenciario sin tener la sensación acuciante de que hubiera el estricto control que por otra parte sin duda debía de estar siendo puesto en práctica en la medida de lo necesario.

Melilla (población real de 257 personas, capacidad ideal de 200) era especial en varios aspectos. Por un lado, obviamente más pequeña y con instalaciones de apariencia más vieja. Había un ambiente de cierto paternalismo condescendiente que se conectaba con el dato de que los funcionarios parecían conocer los nombres y los detalles personales de casi cada recluso. Por otro lado, esta especie de control cercano creaba una atmósfera peculiar, ciertamente diferente al de las otras prisiones, lo que quizás aconseje tomar una cierta distancia en la comparación de los resultados allí obtenidos con los de las prisiones encuestadas en Andalucía oriental.

\section{Hipótesis de partida}

Además de la finalidad general de contribuir al mejor conocimiento del funcionamiento real del sistema penitenciario español y del día a día de la vida en prisión desde la perspectiva de las personas presas, el presente estudio tiene como objetivo específico analizar si la reeducación y reinserción social, elemento fundamental que la Constitución española establece como finalidad de la ejecución de las penas privativas de libertad, es compatible con los resultados de las encuestas llevadas a cabo en los cinco centros penitenciarios mencionados.

A estos efectos, la hipótesis central del trabajo es que la reeducación y la reinserción social en sus aspectos fundamentales son coherentes con los resultados de las encuestas llevadas a cabo en los cinco centros penitenciarios objeto de la muestra, si bien la calidad de vida en prisión varía de unos centros a otros en función de las relaciones, las condiciones y el ambiente, lo cual debe repercutir en la reeducación y reinserción (menor calidad de vida = mayores dificultades en lograr los objetivos).

Para contestar a la hipótesis planteada, las dimensiones o variables generales que se han analizado son las siguientes: a) Percepción de la relación entre internos y funcionarios; b) Percepción de la relación entre internos; c) Percepción del ambiente en prisión y sus repercusiones en la resocialización. En relación con cada una de las mencionadas variables se seleccionaron cinco del cuestionario MQPL (Measuring the Quality of Prison Life), a saber:

a) Percepción de la relación entre internos y funcionarios: s5. Las relaciones entre el personal y los internos son buenas 
s6. Recibo apoyo del personal de esta prisión cuando lo necesito s48. En esta prisión el personal me trata con amabilidad s62. No siento miedo de que el personal me vaya a golpear, insultar, o amenazar

s69. El personal de esta prisión me trata con respeto

b) Percepción de la relación de los internos entre sí:

s66. En mi módulo hay muchas peleas entre internos

s102. En esta prisión hay que estar en un grupo para salir adelante

s107. En esta prisión las drogas provocan muchos problemas entre los internos

s114. En esta prisión puedo relajarme y ser yo mismo en presencia de otros internos

s117. En esta prisión no se tolera que unos internos acosen a otros

c) Percepción del ambiente en prisión y sus repercusiones en la resocialización:

s15. En esta prisión me ayudan a hacer planes para no delinquir cuando salga en libertad

s56. Las condiciones de vida en esta prisión son malas

s59. En general siento que estoy "pasando el tiempo» en vez de "aprovechando el tiempo» de mi condena

s106. La mayor parte del tiempo de mi condena me parece, ante todo, un castigo

s115. El plan individual de tratamiento en esta prisión es útil

Para cada uno de estos - así como, en general, para todas las preguntas que conforman el cuestionario MQPL - los internos tenían cinco opciones de respuesta, debiendo elegir únicamente la que mejor se ajustaba a su percepción personal: "muy de acuerdo», "de acuerdo», «ni de acuerdo ni en desacuerdo», "en desacuerdo» y «muy en desacuerdo».

De cara a confirmar o rechazar la hipótesis planteada anteriormente - a partir del análisis de las referidas tres variables- se realizó en primer lugar un estudio descriptivo de los datos obtenidos a través de una serie de preguntas que se contienen en la primera parte del cuestionario MQPL, y que permiten obtener un perfil de la población penitenciaria. Estos datos son los siguientes: (1) Edad; (2) País de 
Nacimiento; (3) Estado civil; (4) Estudios finalizados; (5) Consumo de drogas previo al ingreso en prisión; (6) Situación actual en prisión (preventivo, cumpliendo condena, etc.); (7) Edad de la primera condena; (8) Primera vez en prisión; (9) Número de veces que han estado en prisión los reincidentes; (10) Tiempo que ha pasado en prisión (en años); (11) Actividad principal durante el día; (12) Pasar 6 horas o más sin actividades, y (13) Calificación que otorgan al centro penitenciario (en una escala de 0 a 10 ).

\section{Metodología}

La criminóloga Alison LIEBLING, directora del Prisons Research Centre (PRC) de la Universidad de Cambridge (UK), es la impulsora de la idea y los principales desarrollos y aplicaciones de las encuestas de medición de la calidad de vida penitenciaria (MQPL, por sus iniciales en inglés: Measuring the Quality of Prison Life). Su obra de referencia es: Prisons and their Moral Performance (Liebling, 2004) y el cuestionario desarrollado por esta autora es la base sobre la que se ha llevado a cabo nuestra investigación.

Naturalmente, el cuestionario fue traducido al castellano, así como se adaptó su terminología y redacción al contexto cultural español y al entorno penitenciario. También se redujo su extenso número de preguntas, de modo que finalmente el cuestionario repartido en las prisiones españolas contenía 53 de los 126 originales de la encuesta MQPL.

Como se ha señalado anteriormente, las encuestas se realizaron en un total de cinco centros situados en Andalucía oriental y en la geográficamente cercana Ciudad Autónoma de Melilla. Previamente se había obtenido el necesario permiso de la autoridad central de la que dependen las instituciones penitenciarias en España.

En cuanto al tamaño de la muestra, teniendo en cuenta que la población típica de la mayor parte de los centros que iban a ser visitados se sitúa entre los 500 y 1.400 internos, se partió de una muestra compuesta por más del 10 por 100 de la población reclusa, tanto hombres como mujeres, con una sobrerrepresentación de estas últimas por su número comparativamente mucho menor, y procurando una distribución uniforme por módulos.

La participación de los internos en estas encuestas fue totalmente voluntaria - algo que se les reiteraba en el momento de repartirles el cuestionario - sin que se les ofreciera ninguna compensación económica o de otro tipo por su participación.

La muestra total está reflejada en el Tabla $I$. 
Tabla I: Muestra por centro y sexo

\begin{tabular}{|c|l|c|c|c|c|c|c|}
\hline \multicolumn{2}{|c|}{} & \multicolumn{6}{|c|}{ Centro penitenciario } \\
\cline { 3 - 9 } \multicolumn{2}{|c|}{} & Almería & Granada & Melilla & Málaga & Jaén & Total \\
\hline \multirow{3}{*}{ Hombres } & N. ${ }^{\circ}$ encuestas & 73 & 119 & 51 & 102 & 50 & 395 \\
\cline { 2 - 9 } & Porcentaje & 92.4 & 82.6 & 92.7 & 85 & 89.3 & 87.0 \\
\hline \multirow{3}{*}{ Mujeres } & N encuestas & 6 & 25 & 4 & 18 & 6 & 59 \\
\cline { 2 - 9 } & Porcentaje & 7.6 & 17.4 & 7.3 & 15.0 & 10.7 & 13.0 \\
\hline \multirow{3}{*}{ Total } & N. ${ }^{\circ}$ encuestas & 79 & 144 & 55 & 120 & 56 & 454 \\
\cline { 2 - 9 } & Porcentaje & 17.4 & 31.7 & 12.1 & 26.4 & 12.3 & 100 \\
\hline
\end{tabular}

Fuente: Elaboración propia.

La selección de los internos se hizo de forma aleatoria, mediante el sencillo procedimiento de señalar, en el listado oficial de internos de cada módulo, a las personas que ocupaban el número 1, 11, 21, 31 y así sucesivamente, lo cual aseguraba que el porcentaje acumulado fuera superior en todo caso al diez por ciento, a fin de cubrir las inevitables fallas. En caso de que el recluso seleccionado no estuviera disponible o bien se negase a participar en la encuesta, su sustituto era el siguiente de la lista cuando la incidencia se detectaba por adelantado; en cambio no había posibilidad de sustitución si la incidencia surgía en el mismo momento de la realización de la encuesta ${ }^{10}$. En todo caso, las cifras de fallos (y, por tanto, de necesidad de sustitución aleatoria) debidos, bien a negativa a participar o a imposibilidad por tener otra actividad planeada o por tener que asistir a juicio, fue pequeño, inferior a su vez al diez por

${ }_{10}$ Algunos de los reclusos que se presentaban a realizar el cuestionario decidían sobre la marcha no hacerlo, ya fuera porque les insistiéramos en su voluntariedad y, ya sin la presencia de los funcionarios, se cercioraban de que ningún perjuicio ni beneficio tangible se iba a derivar para ellos del hecho de que colaborasen o dejasen de colaborar, ya sea porque al ver la extensión del cuestionario se echaban para atrás por no estar dispuestos a emplear una hora u hora y cuarto aproximadamente de su tiempo en contestarlo. También se produjo algún caso puntual de recluso que no se presentó por haberle surgido otra circunstancia a última hora. Hubo también un par de casos, especialmente en Melilla, en los que los reclusos no podían contestar el cuestionario por no entender español, sin que los investigadores pudiéramos ayudarles por no dominar el árabe. En cambio, intervinimos directamente leyendo las preguntas a algunos reclusos que no podían leerlas por problemas de presbicia sin que tuvieran las gafas de leer a mano, y traduciéndolas a algunos otros que no dominaban el español pero sí otros idiomas que los investigadores sí hablamos, en particular francés, inglés y alemán. Hemos de subrayar no obstante que estas últimas incidencias en las que tuvimos que leer o traducir y anotar las respuestas fueron extremadamente puntuales, no más dos o tres reclusos por centro penitenciario, y naturalmente no están contabilizadas entre las ausencias que se indican en el texto de los datos de las encuestas efectivamente contestadas. 
ciento del total de reclusos seleccionados y con diferencias poco significativas por centros penitenciarios.

El número de reclusos que hubo que reemplazar por adelantado debido a su negativa a participar o a que tenían una actividad programada incompatible con la encuesta fue: Almería: 6 (6 hombres); Granada: 7 (5 hombres, 2 mujeres); Jaén: 4 (4 hombres); Málaga: 9 (7 hombres, 2 mujeres); Melilla: 2 (2 hombres); TOTAL: 28 (24 hombres, 4 mujeres)

El número de reclusos que no contestaron el cuestionario por no presentarse en el momento de la encuesta sin que hubiera posibilidad de reemplazarlos, o por negativa de última hora fue: Almería: 1 (1 hombre) ninguna negativa; Granada: 9 (8 hombres, 1 mujer) 3 de los cuales negativas ( 2 hombres, 1 mujer); Jaén: 6 (6 hombres) 2 de los cuales negativas; Málaga: 4 (3 hombres, 1 mujer) 1 de los cuales negativa (1 hombre); Melilla: 0; TOTAL: 20 (18 hombres, 2 mujeres).

Una incidencia adicional fue que un número igualmente pequeño de reclusos simularon hacer el cuestionario pero en realidad lo dejaron en blanco por completo o en su mayor parte, por lo que hubo naturalmente que descartarlos y no están incluidos en las cifras indicadas a continuación de cuestionarios efectivamente respondidos. El número de cuestionarios defectuosos que no pudo ser procesado por ausencia parcial o total de respuestas fue: Almería: 1 (1 hombre); Granada: 9 (8 hombres, 1 mujer); Jaén: 2 (2 hombres); Málaga: 2 (2 hombres); Melilla: 2 (1 hombre); TOTAL: 16 (15 hombres, 1 mujer).

Una vez recabados los cuestionarios que previamente habían sido cumplimentados por la población penitenciaria de los cinco centros objeto de estudio, su contenido fue grabado en IBM SPSS Statistics 20 con el objetivo de facilitar el análisis.

\subsection{Tests estadísticos}

El análisis de los resultados comenzó con la elaboración del perfil sociodemográfico de los encuestados, para después concretarlo por centros y analizar las diferencias entre los distintos establecimientos penitenciarios. Tras el análisis descriptivo, se dio paso al análisis bivariado, en el que se cruzaron los indicadores expuestos sobre las 3 hipótesis -relaciones interno-funcionario, relaciones entre internos y el ambiente en prisión y su función en la resocialización - con la variable «centro penitenciario».

Para conocer si las diferencias reveladas eran significativas estadísticamente se empleó chi cuadrado, siendo significativos al 95\% aquellos resultados cuyo nivel de significación -n.s. de ahora en adelante-fuera inferior a 0.05. Posteriormente, se aplicó el coeficiente Eta para cruces entre variables nominales y escala, profundizando así sobre la fuerza de 
las asociaciones resultantes — siendo 1 asociación perfecta y 0 independencia-.

Una vez conocidas las diferencias significativas que ocurrían entre los centros en los distintos indicadores, se procedió a construir los índices de percepción para cada una de las dimensiones abordadas en el estudio: relaciones interno-funcionario, entre internos, y el ambiente carcelario y su repercusión en la reinserción social. Para la construcción de los índices, se procedió a sumar las puntuaciones de los 5 indicadores seleccionados previa inversión del orden de las respuestas en aquellas preguntas cuyo sentido es negativo ${ }^{11}$. Tras ello, se dividió entre 5 para que los límites de variabilidad del índice oscilaran entre 1 y 5 . Una vez finalizada esta operación, las variables resultantes se recodificaron en una nueva variable respectivamente siguiendo la reasignación: desde 1 hasta 1,6 $=1$; desde 1,6 hasta 2,6 =2; desde 2,6 hasta 3,6 $=3$; desde 3,6 hasta 4,6 $=4$; desde 4,6 a $5=5$. Finalmente, a cada valor resultante se le asignó su correspondiente etiqueta, siguiendo las puntuaciones conferidas en la escala original: $1=$ muy buena; 2 = buena; 3 = ni buena ni mala; 4 = mala; $5=$ muy mala.

Finalmente, de nuevo se calculó chi cuadrado para conocer si existía asociación y si las diferencias encontradas en los índices en función del centro penitenciario eran significativas, concretando la fuerza de la asociación mediante Eta.

\section{Resultados}

\subsection{Perfil de la población penitenciaria}

En cuanto al perfil socio-demográfico de los reclusos de las cinco instituciones objeto de estudio, en la Tabla I y la Tabla II puede apreciarse que el interno prototípico era hombre, con una edad media de 40 años (con una desviación típica de 11,1 años), de nacionalidad española $(83,1 \%)$, soltero con pareja $(34.3 \%)$, con estudios secundarios $(43.2 \%)$, consumidor habitual de drogas antes de su entrada en prisión (54.0\%) y cumpliendo su primera condena (55.2\%). Su edad media cuando fueron condenados por primera vez era de 29 años (desviación típica, 12,4 años), y la mayor parte de ellos estaban cumpliendo condena (67.7\%) en lugar de preventivamente privados de libertad. De media califican la calidad del establecimiento penitenciario en el que se encuentran con una nota de 5,3 (desviación típica, 2.3).

11 Así, por ejemplo, estar de acuerdo con la frase «el personal me trata con amabilidad» es positivo, mientras que en el caso de la afirmación «hay muchas peleas entre internos», la respuesta positiva es, obviamente, la que expresa desacuerdo. Similarmente, en las preguntas de significado inverso el muy de acuerdo se considera muy negativo y el muy en desacuerdo, muy positivo. 
Tabla II: Perfil de la población penitenciaria (porcentajes y medias)

\begin{tabular}{|c|c|c|c|c|c|c|c|}
\hline & \multicolumn{6}{|c|}{ Centro penitenciario } \\
\hline & & Almería & Granada & Melilla & Málaga & Jaén & Total \\
\hline \multirow{2}{*}{ Edad } & Media & 41.0 & 43.0 & 39.0 & 38.0 & 36.0 & 40.0 \\
\hline & Desviación típica & 10.0 & 10.0 & 12.0 & 12.0 & 11.0 & 11.1 \\
\hline \multirow{3}{*}{ País de nacimiento } & España & 75.3 & 87.9 & 75.9 & 81.2 & 92.7 & 83.1 \\
\hline & Marruecos & 11.7 & 2.1 & 20.4 & 8.5 & 1.8 & 7.7 \\
\hline & Otros & 13.0 & 10.0 & 3.7 & 10.3 & 5.5 & 9.3 \\
\hline \multirow{4}{*}{ Estado civil } & Soltero con pareja & 32.1 & 32.1 & 37.7 & 37.5 & 32.7 & 34.3 \\
\hline & Casado & 25.6 & 25.7 & 32.1 & 23.3 & 27.3 & 26.0 \\
\hline & Soltero sin pareja & 19.2 & 24.3 & 13.2 & 21.7 & 30.9 & 22.2 \\
\hline & Otros & 23.1 & 17.9 & 17.0 & 17.5 & 9.1 & 17.5 \\
\hline \multirow{3}{*}{ Estudios } & Primarios & 44.9 & 47.9 & 26.4 & 35.6 & 30.9 & 39.4 \\
\hline & Secundarios & 46.2 & 47.1 & 66.0 & 56.8 & 65.5 & 43.2 \\
\hline & Educación superior & 9.0 & 5.0 & 7.5 & 7.6 & 3.6 & 17.3 \\
\hline \multirow{2}{*}{$\begin{array}{l}\text { Consumo de } \\
\text { drogas previo a } \\
\text { ingreso en prisión }\end{array}$} & Sí & 44.0 & 51.1 & 29.4 & 65.0 & 74.5 & 54.0 \\
\hline & No & 56.0 & 48.9 & 70.6 & 35.0 & 25.5 & 46.0 \\
\hline \multirow[t]{2}{*}{ Situación actual } & $\begin{array}{l}\text { Cumpliendo } \\
\text { condena }\end{array}$ & 69.7 & 73.4 & 79.6 & 55.9 & 64.3 & 67.7 \\
\hline & Otros & 30.3 & 26.6 & 20.4 & 44.1 & 35.7 & 32.3 \\
\hline \multirow{2}{*}{$\begin{array}{l}\text { Edad de la primera } \\
\text { condena }\end{array}$} & Media & 29.0 & 28.0 & 30.0 & 31.0 & 28.0 & 29.20 \\
\hline & Desviación típica & 11.0 & 11.0 & 12.0 & 14.0 & 13.0 & 12.4 \\
\hline \multirow{2}{*}{$\begin{array}{l}\text { Primera vez en } \\
\text { prisión }\end{array}$} & Sí & 67.1 & 47.8 & 67.9 & 51.3 & 53.6 & 55.2 \\
\hline & No & 32.9 & 52.2 & 32.1 & 48.7 & 46.4 & 44.8 \\
\hline \multirow{4}{*}{$\begin{array}{l}\text { N. } .^{\circ} \text { de veces que } \\
\text { ha estado antes } \\
\text { en prisión (sólo } \\
\text { reincidentes) }\end{array}$} & 1 & 38.5 & 27.0 & 48.1 & 34.5 & 19.2 & 31.9 \\
\hline & 2 & 23.1 & 27.0 & 18.5 & 29.3 & 30.8 & 26.5 \\
\hline & 3 & 23.1 & 14.6 & 14.8 & 13.8 & 23.1 & 15.9 \\
\hline & Más de 3 & 15.4 & 31.5 & 18.5 & 22.4 & 26.9 & 25.7 \\
\hline \multirow{2}{*}{$\begin{array}{l}\text { Tiempo que ha } \\
\text { pasado en esta } \\
\text { prisión (en años) }\end{array}$} & $\begin{array}{l}\text { Menos de un año y } \\
\text { medio }\end{array}$ & 57.7 & 47.8 & 82.4 & 82.5 & 46.3 & 62.7 \\
\hline & Otros & 42.3 & 52.2 & 17.6 & 17.5 & 53.7 & 37.3 \\
\hline \multirow{2}{*}{$\begin{array}{l}\text { Actividad principal } \\
\text { durante el día }\end{array}$} & Escuela & 53.3 & 20.2 & 29.3 & 42.7 & 37.1 & 35.4 \\
\hline & Otras & 46.7 & 79.8 & 70.7 & 57.3 & 62.9 & 64.6 \\
\hline \multirow{2}{*}{$\begin{array}{l}\text { Pasa más de } \\
\text { seis horas sin } \\
\text { actividades }\end{array}$} & Sí & 47.3 & 35.3 & 50.0 & 41.4 & 38.5 & 41.2 \\
\hline & No & 52.7 & 64.7 & 50.0 & 58.6 & 61.5 & 58.8 \\
\hline \multirow{2}{*}{$\begin{array}{l}\text { Calificación } \\
\text { del centro } \\
\text { penitenciario } \\
\end{array}$} & Media & 5.7 & 5.2 & 5.6 & 5.4 & 4.5 & 5.3 \\
\hline & Desviación típica & 1.9 & 2.1 & 2.9 & 2.2 & 2.6 & 2.3 \\
\hline $\begin{array}{l}\text { Tamaño de la } \\
\text { muestra }\end{array}$ & & 79 & 144 & 55 & 120 & 56 & 454 \\
\hline
\end{tabular}

Fuente: Elaboración propia. 
La Tabla II refleja asimismo que el perfil socio-demográfico de la muestra varía de uno a otro de los cinco centros de nuestro estudio. La edad media total era de 40 años, pero por ejemplo los internos de Jaén eran los más jóvenes (media de 36 años con desviación típica de 11,0) frente a una edad media más alta en Granada (43 años y desviación de $10,0)$.

También había diferencias en cuanto al nivel educativo: la mayor parte de los reclusos en Almería y Granada sólo habían superado los estudios primarios, mientras que la mayoría en las otras prisiones había completado la educación secundaria. Con respecto al consumo de drogas antes de entrar en prisión, la mayor parte de los internos de Almería y Melilla afirmaron no consumir. Por lo demás, el establecimiento penitenciario de Granada era el único en el que la mayoría de los reclusos tenían la experiencia de haber sido encarcelados previamente.

Por lo que hace referencia a la calificación global proporcionada por los encuestados de cada centro también se revelan diferencias destacables. Así, el centro penitenciario de Almería obtuvo la máxima puntuación con un 5,7, mientras que los internos de la prisión de Jaén otorgaron a ésta un suspenso $(4,5)$. Esta última puntuación puede que tenga carácter coyuntural, condicionada por el contexto en el que se realizó la encuesta: cuando se acudió a este centro penitenciario, la zona donde se ubica el mismo estaba sufriendo una inusual ola de calor para la época (mediados de mayo), con temperaturas cercanas a los cuarenta grados centígrados. Esta circunstancia hizo que los internos se quejasen reiteradamente de la falta de aire acondicionado y de duchas en las celdas, lo cual muy probablemente repercutió en sentido negativo en la calificación otorgada al centro. Por lo demás, como podrá apreciarse en los resultados detallados infra, las respuestas dadas por los internos de Jaén en los cuestionarios revelan una general satisfacción en cuanto a los diferentes aspectos de su vida penitenciaria que fueron objeto de medición en la encuesta.

\subsection{Percepción de las relaciones entre reclusos y personal del centro}

La Tabla III (última columna de la derecha) muestra que, en el conjunto de los cinco centros penitenciarios, un 50,5\% de los reclusos encuestados estaba «de acuerdo» o «muy de acuerdo» con la afirmación de que las relaciones con el personal del respectivo centro penitenciario eran buenas, mientras que un 53,7\% estaba «de acuerdo» o «muy de acuerdo» en la afirmación relacionada con el apoyo que el personal de prisión les proporcionaba. Por su parte, el $45 \%$ de los encuestados se mostró conforme con la afirmación que establecía que eran tratados con amabilidad por parte del personal, mientras que un 51,6\% manifestó 
conformidad («muy de acuerdo» o «de acuerdo») con la afirmación que declara un trato respetuoso por parte del personal. Finalmente, el 45,5\% de los internos encuestados declaró estar «de acuerdo» $\mathrm{O}$ «muy de acuerdo» con la afirmación que señala la ausencia de miedo ante cualquier tipo de actitud vejatoria por parte del personal hacia ellos.

\section{Tabla III: Percepción de las relaciones internos-funcionarios por centro penitenciario (porcentajes)}

\begin{tabular}{|c|c|c|c|c|c|c|c|}
\hline & \multicolumn{6}{|c|}{ Centro Penitenciario } \\
\hline & & Almería & Granada & Melilla & Málaga & Jaén & Total \\
\hline \multirow{5}{*}{$\begin{array}{l}\text { Las } \\
\text { relaciones } \\
\text { entre el } \\
\text { personal y } \\
\text { los internos } \\
\text { son buenas }\end{array}$} & Muy de acuerdo & 25,0 & 15,3 & 38,2 & 12,5 & 26,8 & 20,4 \\
\hline & De acuerdo & 36,3 & 22,2 & 32,7 & 37,5 & 23,2 & 30,1 \\
\hline & $\begin{array}{l}\text { Ni de acuerdo ni } \\
\text { en desacuerdo }\end{array}$ & 25,0 & 37,5 & 16,4 & 34,2 & 28,6 & 30,8 \\
\hline & En desacuerdo & 10,0 & 12,5 & 7,3 & 11,7 & 12,5 & 11,2 \\
\hline & \begin{tabular}{|l} 
Muy en \\
desacuerdo
\end{tabular} & 3,8 & 12,5 & 5,5 & 4,2 & 8,9 & 7,5 \\
\hline \multirow{5}{*}{$\begin{array}{l}\text { Recibo } \\
\text { apoyo del } \\
\text { personal de } \\
\text { esta prisión } \\
\text { cuando lo } \\
\text { necesito }\end{array}$} & Muy de acuerdo & 26,3 & 11,8 & 41,8 & 15,8 & 25,0 & 20,7 \\
\hline & \begin{tabular}{|l|} 
De acuerdo \\
\end{tabular} & 32,5 & 27,1 & 21,8 & 41,7 & 41,1 & 33,0 \\
\hline & $\begin{array}{l}\text { Ni de acuerdo ni } \\
\text { en desacuerdo }\end{array}$ & 18,8 & 20,1 & 16,4 & 18,3 & 12,5 & 18,0 \\
\hline & En desacuerdo & 12,5 & 19,4 & 9,1 & 15,0 & 10,7 & 14,7 \\
\hline & $\begin{array}{l}\text { Muy en } \\
\text { desacuerdo }\end{array}$ & 10,0 & 21,5 & 10,9 & 9,2 & 10,7 & 13,6 \\
\hline \multirow{5}{*}{$\begin{array}{l}\text { Aquí el } \\
\text { personal me } \\
\text { trata con } \\
\text { amabilidad }\end{array}$} & Muy de acuerdo & 12,5 & 12,5 & 29,1 & 11,7 & 17,9 & 14,9 \\
\hline & De acuerdo & 38,8 & 17,4 & 38,2 & 37,5 & 26,8 & 30,1 \\
\hline & $\begin{array}{l}\text { Ni de acuerdo ni } \\
\text { en desacuerdo }\end{array}$ & 35,0 & 34,7 & 18,2 & 39,2 & 37,5 & 34,3 \\
\hline & \begin{tabular}{|l|} 
En desacuerdo \\
\end{tabular} & 6,3 & 13,9 & 9,1 & 8,3 & 8,9 & 9,9 \\
\hline & \begin{tabular}{|l|} 
Muy en \\
desacuerdo
\end{tabular} & 7,5 & 21,5 & 5,5 & 3,3 & 8,9 & 10,8 \\
\hline \multirow{5}{*}{$\begin{array}{l}\text { No siento } \\
\text { miedo de que } \\
\text { el personal } \\
\text { me vaya } \\
\text { a golpear, } \\
\text { insultar, o } \\
\text { amenazar }\end{array}$} & Muy de acuerdo & 28,8 & 23,6 & 32,7 & 20,8 & 14,3 & 23,7 \\
\hline & De acuerdo & 22,5 & 22,9 & 16,4 & 22,5 & 21,4 & 21,8 \\
\hline & $\begin{array}{l}\text { Ni de acuerdo ni } \\
\text { en desacuerdo }\end{array}$ & 23,8 & 20,1 & 32,7 & 23,3 & 19,6 & 23,1 \\
\hline & En desacuerdo & 6,3 & 11,1 & 12,7 & 20,0 & 28,6 & 14,9 \\
\hline & \begin{tabular}{|l|} 
Muy en \\
desacuerdo
\end{tabular} & 18,8 & 22,2 & 5,5 & 13,3 & 16,1 & 16,5 \\
\hline \multirow{5}{*}{$\begin{array}{l}\text { El personal } \\
\text { de esta } \\
\text { prisión me } \\
\text { trata con } \\
\text { respeto }\end{array}$} & Muy de acuerdo & 18,8 & 15,3 & 30,9 & 18,3 & 19,6 & 19,1 \\
\hline & De acuerdo & 38,8 & 23,6 & 32,7 & 38,3 & 33,9 & 32,5 \\
\hline & $\begin{array}{l}\text { Ni de acuerdo ni } \\
\text { en desacuerdo }\end{array}$ & 33,8 & 31,9 & 27,3 & 29,2 & 21,4 & 29,7 \\
\hline & En desacuerdo & 3,8 & 12,5 & 3,6 & 10,0 & 12,5 & 9,2 \\
\hline & $\begin{array}{l}\text { Muy en } \\
\text { desacuerdo }\end{array}$ & 5,0 & 16,7 & 5,5 & 4,2 & 12,5 & 9,5 \\
\hline
\end{tabular}

Fuente: Elaboración propia. 
Es notable el amplio porcentaje que la opción de respuesta «ni de acuerdo ni en desacuerdo" obtuvo en algunos de los agrupados en esta primera variable. Así, por ejemplo, en la pregunta relativa al trato amable por parte del personal, un $34,3 \%$ de los internos de los cinco centros penitenciarios eligió la opción «ni de acuerdo ni en desacuerdo». Se trata de un fenómeno que se presenta asimismo en no pocas otras ocasiones en los resultados de la presente investigación. Esto puede atribuirse con carácter general (puesto que no necesariamente son relevantes en relación con cada ítem) a diversos. En primer lugar hay que tener en cuenta que algunos internos mostraban dificultades a la hora de comprender los matices de determinadas preguntas, ya sea debido a su escasa formación educativa o bien - en el caso de ciudadanos extranjeros- a dificultades para comprender el español. En segundo lugar, y en este caso centrando la explicación en la segunda dimensión objeto de estudio (relaciones internos-internos), la razón que explicaría el amplio porcentaje de «indecisos» vendría dada por la posible prudencia de algunos internos antes de admitir la existencia de peleas entre internos o el tráfico de drogas. Por supuesto, sería un temor completamente infundado, por el carácter anónimo del cuestionario y porque ningún otro recluso ni funcionario iba a tener jamás acceso a ninguno de los cuestionarios; aun así, un porcentaje de los reclusos podría albergar cierta desconfianza, además de que en esta materia rige un cierto mutismo y el rechazo a lo que podría considerarse como una especie de delación. En tercer lugar es relevante que el número de preguntas que tenían que contestar los internos era considerable; de hecho, tuvimos en ocasiones la impresión de que, en la parte final del mismo y debido al cansancio, algunos internos perdían motivación y podían sentirse inclinados a elegir la opción de respuesta neutra para con ello ir avanzando más rápidamente en la cumplimentación del cuestionario.

En cuanto a la posible existencia de diferencias en la percepción de la relación con los funcionarios del centro penitenciario en función de estar internado en uno u otro centro de los cinco encuestados (Tabla III), se observan discrepancias, sin perjuicio de que, como ya se ha señalado, hay un peso notable de la opción neutra de respuesta. Ésta representa, dependiendo de la prisión y de la pregunta, desde un mínimo de 12,5\% hasta un máximo del 39,2\% de los casos.

En efecto, con respecto a determinadas cuestiones se observan claras diferencias en función del centro penitenciario en el que se está recluido. Así, ante la afirmación que versa sobre el apoyo recibido por parte del personal de la prisión, el 66,1\% de los encuestados de la prisión de Jaén se mostraba «de acuerdo» o «muy de acuerdo» con esta afirmación. Frente a ello, un 38,9\% de los encuestados del centro penitenciario de Granada agrupó sus respuestas en torno a las opciones «de acuerdo» o «muy de acuerdo». Lo mismo cabe decir, por ejemplo, en relación a la afirmación relativa al trato amable por parte de los funcionarios: mientras que un $67,3 \%$ de los internos de la prisión de Melilla agrupó sus 
respuestas en torno a las opciones «de acuerdo» o "muy de acuerdo», en cambio apenas un $29,9 \%$ de los internos del centro penitenciario de Granada señaló esas mismas dos opciones de respuesta.

\subsubsection{Análisis de chi cuadrado y Eta}

Una vez expuesta la distribución porcentual de cada una de las variables ya mencionadas producida en cada uno de los centros penitenciarios en los que se recopilaron los cuestionarios, en la Tabla $I V$, la prueba de $\chi^{2}$ (chi cuadrado) demuestra la existencia de asociación significativa entre los indicadores referentes a la relación entre los internos y el personal de la prisión por «centro penitenciario».

\section{Tabla IV: Medidas de asociación para las relaciones internos- funcionario y centro penitenciario}

\begin{tabular}{|l|c|c|l|c|}
\hline & \multicolumn{2}{|c|}{ Pruebas de chi-cuadrado } & \multicolumn{2}{c|}{ Medidas direccionales } \\
\cline { 2 - 5 } & $\begin{array}{l}\text { Chi-cuadrado } \\
\text { de Pearson }\end{array}$ & $\begin{array}{l}\text { Sig. asintótica } \\
\text { (bilateral) }\end{array}$ & \multicolumn{2}{|c|}{ Eta (Nominal por Escala) } \\
\hline $\begin{array}{l}\text { Las relaciones } \\
\text { entre el personal } \\
\text { y los internos son } \\
\text { buenas }\end{array}$ & 40,114 & \multirow{2}{*}{, 001} & $\begin{array}{l}\text { Las relaciones ... son } \\
\text { buenas }\end{array}$ &, 219 \\
\cline { 3 - 5 } & \multirow{2}{*}{$\begin{array}{l}\text { Centro penitenciario } \\
\text { dependiente }\end{array}$} &, 027 \\
\hline $\begin{array}{l}\text { Recibo apoyo del } \\
\text { personal de esta } \\
\text { prisión cuando lo } \\
\text { necesito }\end{array}$ & 43,356 & \multirow{2}{*}{, 000} & $\begin{array}{l}\text { Recibo apoyo del } \\
\text { personal... }\end{array}$ &, 240 \\
\cline { 3 - 5 } $\begin{array}{l}\text { Aquí el personal } \\
\text { me trata con } \\
\text { amabilidad }\end{array}$ & 55,785 & \multirow{2}{*}{$\begin{array}{l}\text { Centro penitenciario } \\
\text { dependiente }\end{array}$} &, 117 \\
\hline $\begin{array}{l}\text { No siento } \\
\text { miedo de que } \\
\text { el personal me } \\
\text { vaya a golpear, } \\
\text { insultar o } \\
\text { amenazar }\end{array}$ & 31,763 & \multirow{2}{*}{$\begin{array}{l}\text { El personal ... me } \\
\text { trata con amabilidad }\end{array}$} &, 270 \\
\cline { 3 - 5 } $\begin{array}{l}\text { El personal de } \\
\text { esta prisión me } \\
\text { trata con respeto }\end{array}$ & 34,508 & \multirow{2}{*}{$\begin{array}{l}\text { Centro penitenciario } \\
\text { dependiente }\end{array}$} &, 118 \\
\hline
\end{tabular}

Fuente: Elaboración propia. 
De esta manera, la existencia de relación entre dichas variables, revela que hay diferencias estadísticamente significativas entre los centros analizados (nivel de significación $<0,05$ ) en los 5 indicadores. Además, las relaciones significativas más consistentes se observaron en los cruces entre «recibo apoyo del personal de esta prisión cuando lo necesito» por «centro penitenciario» (n.s. 0,000); y «aquí el personal me trata con amabilidad» por «centro penitenciario» (n.s. 0,000).

Por otro lado, a pesar de que la existencia de relación sea positiva y significativa, la medida direccional Eta nos indica que la intensidad de dichas relaciones no era muy fuerte, pues en ningún caso supera el 0,3 (siendo un estadístico cuyos valores oscilan entre 0 y 1 ).

\subsection{Percepción de las relaciones de los internos entre sí}

En el acumulado de los cinco centros, la distribución porcentual de los valores contestados por la población penitenciaria en las cinco preguntas seleccionadas para conocer su percepción sobre la relación entre internos (Tabla $V$, última columna de la derecha) permite comprobar que entre un $31 \%$ de los encuestados seleccionó su respuesta en torno a la opción "ni de acuerdo ni en desacuerdo», y ello con respecto a tres cuestiones en concreto. Ya se ha argumentado sobre las posibles explicaciones de este fenómeno, que adquiere un perfil peculiar cuando de por medio está la posible sombra de poder ser considerados chivatos o delatores si se reconocen peleas o tráfico de drogas dentro de la prisión.

Por otra parte, hay que destacar el dato de que el 60,8\% de los encuestados en las cinco prisiones declaró no estar de acuerdo con que hubiera una elevada presencia de peleas en su módulo, mientras que el 45,3\% discrepaba de la necesidad de formar parte de un grupo para «salir adelante». Como contraposición a lo anterior, un 48,3\% de los reclusos encuestados (de los cinco centros penitenciarios), manifestaba su grado de acuerdo (opciones "de acuerdo» o «muy de acuerdo») con respecto a los problemas que causan las drogas.

Si con respecto a la dimensión relativa a la percepción de la relación entre internos se analizan por separado los cinco centros penitenciarios, puede observarse la existencia de diferencias significativas en consideración algunas de las cinco afirmaciones que componen esta segunda variable (Tabla $V)$. Así, en relación a la afirmación que establece que «en esta prisión no se tolera que unos internos acosen a otros», nada menos que un $61,3 \%$ de los internos de la prisión de Almería señalan estar «de acuerdo» o «muy de acuerdo» con dicha afirmación, mientras que -nuevamente - en el caso de los reclusos de Granada un escaso $34 \%$ manifiesta su conformidad. Lo mismo cabe decir, por ejemplo, en relación con la afirmación de que las drogas causan muchos problemas entre los internos. Efectivamente, mientras que apenas un 27,2\% 
de los internos del centro penitenciario de Melilla manifiesta estar «de acuerdo" o "muy de acuerdo» con dicha afirmación, dicho porcentaje se eleva hasta el 59\% con respecto a los reclusos de la prisión de Granada. En el resto de preguntas el grado de coincidencia entre los centros es mayor, si bien la prisión de Granada suele presentar unos resultados de respuesta extremos.

\section{Tabla V: Percepción de las relaciones internos-internos por centro penitenciario (porcentajes)}

\begin{tabular}{|c|c|c|c|c|c|c|c|}
\hline & \multicolumn{6}{|c|}{ Centro Penitenciario } \\
\hline & & Almería & Granada & Melilla & Málaga & Jaén & Total \\
\hline \multirow{5}{*}{$\begin{array}{l}\text { En este módulo } \\
\text { hay muchas } \\
\text { peleas entre } \\
\text { internos }\end{array}$} & Muy de acuerdo & 7,5 & \begin{tabular}{|l|}
7,6 \\
\end{tabular} & 7,3 & \begin{tabular}{|l|}
8,3 \\
\end{tabular} & 7,1 & 7,7 \\
\hline & De acuerdo & 5,0 & 8,3 & 0,0 & 10,0 & 16,1 & 8,1 \\
\hline & $\begin{array}{l}\text { Ni de acuerdo ni en } \\
\text { desacuerdo }\end{array}$ & 23,8 & 22,9 & 25,5 & 24,2 & 19,6 & 23,3 \\
\hline & En desacuerdo & 30,0 & 25,0 & 34,5 & 35,8 & 19,6 & 29,2 \\
\hline & Muy en desacuerdo & 33,8 & 36,1 & 32,7 & 21,7 & 37,5 & 31,6 \\
\hline \multirow{5}{*}{$\begin{array}{l}\text { En esta prisión } \\
\text { hay que estar } \\
\text { en un grupo } \\
\text { para salir } \\
\text { adelante }\end{array}$} & Muy de acuerdo & 5,0 & 14,6 & 14,5 & 5,0 & 14,3 & 10,3 \\
\hline & De acuerdo & 15,0 & 20,8 & 14,5 & 12,5 & 16,1 & 16,3 \\
\hline & $\begin{array}{l}\text { Ni de acuerdo ni en } \\
\text { desacuerdo }\end{array}$ & 30,0 & 29,9 & 21,8 & 28,3 & 26,8 & 28,1 \\
\hline & En desacuerdo & 23,8 & 19,4 & 25,5 & 39,2 & 28,6 & 27,3 \\
\hline & Muy en desacuerdo & 26,3 & 15,3 & 23,6 & 15,0 & 14,3 & 18,0 \\
\hline \multirow{5}{*}{$\begin{array}{l}\text { En esta prisión } \\
\text { las drogas } \\
\text { provocan } \\
\text { muchos } \\
\text { problemas } \\
\text { entre los } \\
\text { internos }\end{array}$} & Muy de acuerdo & 23,8 & 36,1 & 12,7 & 29,2 & 17,9 & 27,0 \\
\hline & De acuerdo & 15,0 & 22,9 & 14,5 & 25,8 & 23,2 & 21,3 \\
\hline & $\begin{array}{l}\text { Ni de acuerdo ni en } \\
\text { desacuerdo }\end{array}$ & 38,8 & 25,0 & 34,5 & 31,7 & 30,4 & 31,0 \\
\hline & En desacuerdo & 12,5 & 9,7 & 20,0 & 10,8 & 17,9 & 12,7 \\
\hline & Muy en desacuerdo & 10,0 & 6,3 & 18,2 & 2,5 & 10,7 & 7,9 \\
\hline \multirow{5}{*}{$\begin{array}{l}\text { En esta } \\
\text { prisión, puedo } \\
\text { relajarme y ser } \\
\text { yo mismo en } \\
\text { presencia de } \\
\text { otros internos }\end{array}$} & Muy de acuerdo & 18,8 & 11,1 & 21,8 & 12,5 & 16,1 & 14,7 \\
\hline & De acuerdo & 35,0 & 22,9 & 27,3 & 32,5 & 37,5 & 29,9 \\
\hline & $\begin{array}{l}\text { Ni de acuerdo ni en } \\
\text { desacuerdo }\end{array}$ & 20,0 & 25,7 & 25,5 & 36,7 & 16,1 & 26,4 \\
\hline & En desacuerdo & 12,5 & 13,2 & 12,7 & 13,3 & 16,1 & 13,4 \\
\hline & Muy en desacuerdo & 13,8 & 27,1 & 12,7 & 5,0 & 14,3 & 15,6 \\
\hline \multirow{5}{*}{$\begin{array}{l}\text { En esta prisión } \\
\text { no se tolera } \\
\text { que unos } \\
\text { internos acosen } \\
\text { a otros }\end{array}$} & Muy de acuerdo & 26,3 & 11,8 & 32,7 & 19,2 & 19,6 & 19,8 \\
\hline & De acuerdo & 35,0 & 22,2 & 18,2 & 27,5 & 30,4 & 26,4 \\
\hline & $\begin{array}{l}\text { Ni de acuerdo ni en } \\
\text { desacuerdo }\end{array}$ & 23,8 & 32,6 & 16,4 & 29,2 & 21,4 & 26,8 \\
\hline & En desacuerdo & 7,5 & 12,5 & 20,0 & 14,2 & 16,1 & 13,4 \\
\hline & Muy en desacuerdo & 7,5 & 20,8 & 12,7 & 10,0 & 12,5 & 13,6 \\
\hline
\end{tabular}

Fuente: Elaboración propia. 


\subsubsection{Análisis de chi cuadrado y Eta}

En el caso de las variables seleccionadas para analizar las relaciones que existen entre los internos de los centros penitenciarios encuestados, el estadístico $\chi^{2}$ muestra diferencias entre la relación de éstas con el «centro penitenciario» en el que se encuentra la población reclusa encuestada. Como se puede apreciar en la Tabla VI, no existe asociación entre la variable «en este módulo hay muchas peleas entre internos» $\mathrm{y}$ "centro penitenciario», por lo que resultó no haber diferencias significativas por centros penitenciarios (n.s. 0,168>0,05). El resto de variables, en contraposición, sí resultaron estar asociadas con el «centro penitenciario» en el que se estuviese cumpliendo condena (n.s. 0,05).

\section{Tabla VI: Medidas de asociación para las relaciones entre internos y centro penitenciario}

\begin{tabular}{|c|c|c|c|c|}
\hline & \multicolumn{2}{|c|}{ Pruebas de chi-cuadrado } & \multirow{2}{*}{\multicolumn{2}{|c|}{$\frac{\text { Medidas direccionales }}{\text { Eta (Nominal por Escala) }}$}} \\
\hline & $\begin{array}{c}\text { Chi-cuadrado } \\
\text { de Pearson }\end{array}$ & $\begin{array}{l}\text { Sig. asintóti- } \\
\text { ca (bilateral) }\end{array}$ & & \\
\hline \multirow{2}{*}{$\begin{array}{l}\text { En este módulo } \\
\text { hay muchas peleas } \\
\text { entre internos }\end{array}$} & \multirow{2}{*}{21,292} & \multirow{2}{*}{168} & $\begin{array}{l}\text { En esta prisión hay } \\
\text { muchas peleas... }\end{array}$ & - \\
\hline & & & $\begin{array}{l}\text { Centro penitenciario } \\
\text { dependiente }\end{array}$ & - \\
\hline \multirow{2}{*}{$\begin{array}{l}\text { En esta prisión } \\
\text { hay que estar en } \\
\text { un grupo para } \\
\text { salir adelante }\end{array}$} & \multirow[t]{2}{*}{29,504} & \multirow[t]{2}{*}{, 021} & $\begin{array}{l}\text { En esta prisión hay } \\
\text { que estar en un } \\
\text { grupo... }\end{array}$ & ,176 \\
\hline & & & $\begin{array}{l}\text { Centro penitenciario } \\
\text { dependiente }\end{array}$ & ,131 \\
\hline \multirow{2}{*}{$\begin{array}{l}\text { En esta prisión las } \\
\text { drogas provocan } \\
\text { muchos problemas } \\
\text { entre los internos }\end{array}$} & \multirow{2}{*}{36,458} & \multirow{2}{*}{, 002} & $\begin{array}{l}\text { Drogas provocan } \\
\text { problemas... }\end{array}$ & ,251 \\
\hline & & & $\begin{array}{l}\text { Centro penitenciario } \\
\text { dependiente }\end{array}$ & ,088 \\
\hline \multirow{2}{*}{$\begin{array}{l}\text { En esta prisión, } \\
\text { puedo relajarme y } \\
\text { ser yo mismo en } \\
\text { presencia de otros } \\
\text { internos }\end{array}$} & \multirow{2}{*}{39,092} & \multirow{2}{*}{, 001} & $\begin{array}{l}\text { Puedo relajarme y ser } \\
\text { yo mismo... }\end{array}$ & , 198 \\
\hline & & & $\begin{array}{l}\text { Centro penitenciario } \\
\text { dependiente }\end{array}$ & ,132 \\
\hline \multirow{2}{*}{$\begin{array}{l}\text { En esta prisión no } \\
\text { se tolera que unos } \\
\text { internos acosen a } \\
\text { otros }\end{array}$} & \multirow{2}{*}{34,432} & \multirow{2}{*}{, 005} & $\begin{array}{l}\text { En esta prisión no se } \\
\text { tolera el acoso... }\end{array}$ & ,200 \\
\hline & & & $\begin{array}{l}\text { Centro penitenciario } \\
\text { dependiente }\end{array}$ & ,075 \\
\hline
\end{tabular}

Fuente: Elaboración propia. 
Eta, por su parte, mostró de nuevo que no era muy fuerte la relación entre las variables utilizadas para mostrar la percepción de los encuestados sobre las relaciones que mantenían con otros internos, a pesar de ser una relación significativa.

\subsection{Percepción del ambiente en prisión y sus repercusiones en la resocialización}

En lo que respecta a la percepción que los internos del conjunto de los cinco centros penitenciarios encuestados tienen del ambiente en prisión y sus repercusiones en la resocialización (Tabla VII, última columna de la derecha), puede comprobarse que el 43,1\% de los encuestados consideran que durante su estancia en prisión se les proporciona ayuda para hacer planes de cara a no delinquir una vez vuelvan a estar en libertad (frente a un 36,3\% que discrepan de ello). Sin embargo, el $37,4 \%$ valora de forma negativa las condiciones de vida en el centro en el que están cumpliendo condena (frente a un 29,4\% que señala estar "en desacuerdo» o "muy en desacuerdo" con dicha afirmación). Por su parte, hay que destacar el hecho de que el $67,7 \%$ de los encuestados considera su condena como un castigo (opciones «de acuerdo» $\mathrm{o}$ "muy de acuerdo»). Finalmente, el 32,8\% de los internos de los cinco centros penitenciarios se encuentra "en desacuerdo» o "muy en desacuerdo» con la afirmación que considera el plan individual de tratamiento como útil (frente a un 32,7\% que señala estar a favor, es decir, apenas una décima por debajo).

Si a continuación se analizan las respuestas dadas por los internos en cada uno de los cinco centros penitenciarios por separado, pueden observarse nuevamente diferencias apreciables (Tabla VII). En este sentido hay que destacar la afirmación que interpreta la estancia en prisión como una pérdida de tiempo. Mientras que un 41,3\% de la población penitenciaria de la prisión de Almería manifestó mostrarse «de acuerdo» o «muy de acuerdo» con la misma, dicho porcentaje alcanza el 60,4\% entre la población penitenciaria recluida en Granada. Destacable es también la diferencia en los porcentajes con respecto a la afirmación que señala que «en esta prisión me ayudan a hacer planes para no delinquir cuando salga en libertad». Así mientras que los porcentajes de reclusos que en las prisiones de Almería, Melilla, Málaga y Jaén señalaron estar "de acuerdo" o "muy de acuerdo" con dicha afirmación se movían entre el 45,4\% y el 53,6\%, en el caso de los internos de la prisión de Granada dicho porcentaje alcanzó apenas un 33,4\%. En relación a la afirmación relativa a las condiciones de vida en prisión, es nuevamente Granada la que arroja los peores porcentajes. 
Tabla VII: Percepción del ambiente en prisión y su repercusión en resocialización por centro (porcentajes)

\begin{tabular}{|c|c|c|c|c|c|c|c|}
\hline & \multicolumn{6}{|c|}{ Centro Penitenciario } \\
\hline & & Almería & Granada & Melilla & Málaga & Jaén & Total \\
\hline \multirow{5}{*}{$\begin{array}{l}\text { En esta prisión } \\
\text { me ayudan a } \\
\text { hacer planes } \\
\text { para no delinquir } \\
\text { cuando salga en } \\
\text { libertad }\end{array}$} & Muy de acuerdo & 21,3 & 14,6 & 23,6 & 16,7 & 28,6 & 19,1 \\
\hline & De acuerdo & 25,0 & 18,8 & 21,8 & 30,0 & 25,0 & 24,0 \\
\hline & $\begin{array}{l}\text { Ni de acuerdo ni } \\
\text { en desacuerdo }\end{array}$ & 23,8 & 16,0 & 27,3 & 20,8 & 21,4 & 20,7 \\
\hline & En desacuerdo & 7,5 & 15,3 & 9,1 & 15,0 & 8,9 & 12,3 \\
\hline & $\begin{array}{l}\text { Muy en } \\
\text { desacuerdo }\end{array}$ & 22,5 & 35,4 & 18,2 & 17,5 & 16,1 & 24,0 \\
\hline \multirow{5}{*}{$\begin{array}{l}\text { Las condiciones } \\
\text { de vida en esta } \\
\text { prisión son malas }\end{array}$} & Muy de acuerdo & 12,5 & 20,8 & 14,5 & 16,7 & 14,3 & 16,7 \\
\hline & De acuerdo & 20,0 & 20,8 & 18,2 & 20,0 & 25,0 & 20,7 \\
\hline & $\begin{array}{l}\text { Ni de acuerdo ni } \\
\text { en desacuerdo }\end{array}$ & 36,3 & 27,8 & 30,9 & 35,0 & 41,1 & 33,2 \\
\hline & En desacuerdo & 20,0 & 18,8 & 23,6 & 23,3 & 16,1 & 20,4 \\
\hline & $\begin{array}{l}\text { Muy en } \\
\text { desacuerdo }\end{array}$ & 11,3 & 11,8 & 12,7 & 5,0 & 3,6 & 9,0 \\
\hline \multirow{5}{*}{$\begin{array}{l}\text { En general } \\
\text { siento que estoy } \\
\text { «pasando el } \\
\text { tiempo» en vez de } \\
\text { «aprovechando el } \\
\text { tiempo» }\end{array}$} & Muy de acuerdo & 27,5 & 40,3 & 43,6 & 29,2 & 25,0 & 33,6 \\
\hline & De acuerdo & 13,8 & 20,1 & 12,7 & 15,8 & 16,1 & 16,5 \\
\hline & $\begin{array}{l}\text { Ni de acuerdo ni } \\
\text { en desacuerdo }\end{array}$ & 22,5 & 11,1 & 27,3 & 27,5 & 12,5 & 19,6 \\
\hline & En desacuerdo & 17,5 & 17,4 & 10,9 & 13,3 & 23,2 & 16,3 \\
\hline & $\begin{array}{l}\text { Muy en } \\
\text { desacuerdo }\end{array}$ & 18,8 & 11,1 & 5,5 & 14,2 & 23,2 & 14,1 \\
\hline \multirow{5}{*}{$\begin{array}{l}\text { Mi condena me } \\
\text { parece, ante todo, } \\
\text { un castigo }\end{array}$} & Muy de acuerdo & 26,3 & 45,1 & 40,0 & 30,0 & 32,1 & 35,6 \\
\hline & De acuerdo & 28,8 & 28,5 & 32,7 & 39,2 & 30,4 & 32,1 \\
\hline & $\begin{array}{l}\text { Ni de acuerdo ni } \\
\text { en desacuerdo }\end{array}$ & 28,8 & 12,5 & 21,8 & 19,2 & 16,1 & 18,7 \\
\hline & En desacuerdo & 10,0 & 5,6 & 3,6 & 9,2 & 17,9 & 8,6 \\
\hline & $\begin{array}{l}\text { Muy en } \\
\text { desacuerdo }\end{array}$ & 6,3 & 8,3 & 1,8 & 2,5 & 3,6 & 5,1 \\
\hline \multirow{5}{*}{$\begin{array}{l}\text { El plan individual } \\
\text { de tratamiento en } \\
\text { esta prisión es útil }\end{array}$} & Muy de acuerdo & 11,3 & 6,9 & 12,7 & 5,8 & 5,4 & 7,9 \\
\hline & De acuerdo & 28,8 & 20,8 & 25,5 & 22,5 & 33,9 & 24,8 \\
\hline & $\begin{array}{l}\text { Ni de acuerdo ni } \\
\text { en desacuerdo }\end{array}$ & 41,3 & 26,4 & 32,7 & 42,5 & 30,4 & 34,5 \\
\hline & En desacuerdo & 10,0 & 16,0 & 14,5 & 17,5 & 16,1 & 15,2 \\
\hline & $\begin{array}{l}\text { Muy en } \\
\text { desacuerdo }\end{array}$ & 8,8 & 29,9 & 14,5 & 11,7 & 14,3 & 17,6 \\
\hline
\end{tabular}

Fuente: Elaboración propia. 


\subsubsection{Análisis de chi cuadrado y Eta}

Tal y como se puede comprobar en la Tabla VIII, la prueba de $\chi^{2}$ resultó demostrar la existencia de asociación entre 4 de las 5 variables que representaban la percepción del ambiente en prisión y su repercusión en la resocialización cruzadas por el centro penitenciario. En esta ocasión, la única variable que no mostró una relación significativa con el «centro penitenciario» fue «las condiciones de vida en esta prisión son malas».

\section{Tabla VIII: Medidas de asociación para el ambiente en prisión y resocialización, y centro penitenciario}

\begin{tabular}{|c|c|c|c|c|}
\hline & \multicolumn{2}{|c|}{ Pruebas de chi-cuadrado } & \multirow{2}{*}{\multicolumn{2}{|c|}{$\begin{array}{c}\text { Medidas direccionales } \\
\text { Eta (Nominal por Escala) }\end{array}$}} \\
\hline & $\begin{array}{c}\text { Chi-cuadrado } \\
\text { de Pearson }\end{array}$ & $\begin{array}{l}\text { Sig. asintótica } \\
\text { (bilateral) }\end{array}$ & & \\
\hline \multirow{2}{*}{$\begin{array}{l}\text { En esta prisión me } \\
\text { ayudan a hacer } \\
\text { planes para no } \\
\text { delinquir cuando } \\
\text { salga en libertad }\end{array}$} & \multirow{2}{*}{28,525} & \multirow{2}{*}{027} & $\begin{array}{l}\text { En esta prisión me } \\
\text { ayudan a hacer } \\
\text { planes... }\end{array}$ & , 198 \\
\hline & & & $\begin{array}{l}\text { Centro penitenciario } \\
\text { dependiente }\end{array}$ & 0,123 \\
\hline \multirow{2}{*}{$\begin{array}{l}\text { Las condiciones de } \\
\text { vida en esta prisión } \\
\text { son malas }\end{array}$} & \multirow{2}{*}{14,149} & \multirow{2}{*}{0,588} & $\begin{array}{l}\text { Las condiciones de } \\
\text { vida son malas }\end{array}$ & - \\
\hline & & & $\begin{array}{l}\text { Centro penitenciario } \\
\text { dependiente }\end{array}$ & - \\
\hline \multirow{2}{*}{$\begin{array}{l}\text { En general siento } \\
\text { que estoy "pasando } \\
\text { el tiempo» en vez } \\
\text { de «aprovechando } \\
\text { el tiempo» }\end{array}$} & \multirow{2}{*}{32,811} & \multirow{2}{*}{,008 } & $\begin{array}{l}\text { Siento que estoy } \\
\text { «pasando el tiempo»... }\end{array}$ & 0,182 \\
\hline & & & $\begin{array}{l}\text { Centro penitenciario } \\
\text { dependiente }\end{array}$ & 0,064 \\
\hline \multirow{2}{*}{$\begin{array}{l}\text { Mi condena me } \\
\text { parece, ante todo, } \\
\text { un castigo }\end{array}$} & \multirow{2}{*}{32,967} & \multirow{2}{*}{, 007} & $\begin{array}{l}\text { Mi condena me parece } \\
\text { un castigo }\end{array}$ &, 136 \\
\hline & & & $\begin{array}{l}\text { Centro penitenciario } \\
\text { dependiente }\end{array}$ & 0,131 \\
\hline \multirow{2}{*}{$\begin{array}{l}\text { El plan individual } \\
\text { de tratamiento en } \\
\text { esta prisión es útil }\end{array}$} & \multirow{2}{*}{34,807} & \multirow{2}{*}{,004 } & $\begin{array}{l}\text { El plan individual de } \\
\text { tratamiento es útil }\end{array}$ & 198 \\
\hline & & & $\begin{array}{l}\text { Centro penitenciario } \\
\text { dependiente }\end{array}$ & 0,096 \\
\hline
\end{tabular}

Fuente: Elaboración propia. 
Finalmente, los valores adoptados por el estadístico Eta siguen en consonancia con los anteriores bloques, demostrando que la relación no era muy fuerte.

\section{5. Índices de percepción de las relaciones entre internos y funcionarios, internos entre sí, y el ambiente en prisión y su repercusión en la resocialización}

Una vez analizados los indicadores seleccionados, en la Tabla IX se recopilan las distribuciones porcentuales de los índices de percepción sobre tres aspectos de la vida penitenciaria: 1) las relaciones de los internos con el personal de prisiones, 2) las relaciones que mantienen los internos entre sí y, finalmente, 3) el ambiente en prisión y sus repercusiones en la resocialización. Todos ellos con resultados acumulados de los cinco establecimientos penitenciarios (última columna de la derecha), así como desagregados por centros. Con el apoyo de algunos gráficos comentaremos los índices, tanto en sus resultados totales como por centros.

\section{Tabla IX: Índices de Percepción por Centro Penitenciario (Porcentajes)}

\begin{tabular}{|c|c|c|c|c|c|c|c|}
\hline & \multicolumn{6}{|c|}{ Centro Penitenciario } \\
\hline & & Almería & Granada & Melilla & Málaga & Jaén & Total \\
\hline \multirow{5}{*}{$\begin{array}{l}\text { Índice de } \\
\text { percepción sobre } \\
\text { las relaciones } \\
\text { entre internos y } \\
\text { funcionarios }\end{array}$} & Muy buena & 15,0 & \begin{tabular}{|l|}
9,8 \\
\end{tabular} & 27,3 & 9,2 & 14,3 & 13,2 \\
\hline & Buena & 50,0 & 31,9 & 45,4 & 47,5 & 48,2 & 42,9 \\
\hline & Ni buena ni mala & 26,3 & 36,1 & 20,0 & 34,2 & 17,9 & 29,7 \\
\hline & Mala & 7,5 & 16,0 & 5,5 & 9,2 & 17,9 & 11,6 \\
\hline & Muy mala & 1,3 & 6,2 & 1,8 & 0,0 & 1,8 & 2,6 \\
\hline \multirow{5}{*}{$\begin{array}{l}\text { Índice de } \\
\text { percepción sobre } \\
\text { las relaciones } \\
\text { entre internos }\end{array}$} & Muy buena & 6,3 & 4,9 & 18,2 & 4,2 & 8,9 & 7,1 \\
\hline & Buena & 51,2 & 28,4 & 36,3 & 37,5 & 28,6 & 35,8 \\
\hline & Ni buena ni mala & 38,7 & 45,1 & 34,5 & 50,0 & 51,8 & 44,8 \\
\hline & Mala & 3,8 & 19,4 & 9,1 & 7,5 & 8,9 & 11,0 \\
\hline & Muy mala & 0,0 & 2,1 & 1,8 & 0,8 & 1,8 & 1,3 \\
\hline \multirow{5}{*}{$\begin{array}{l}\text { Índice de } \\
\text { percepción sobre } \\
\text { el ambiente en } \\
\text { prisión y sus } \\
\text { repercusiones en } \\
\text { la resocialización }\end{array}$} & Muy buena & 0,0 & 2,8 & 0,0 & 0,8 & 3,6 & 1,5 \\
\hline & Buena & 41,3 & 13,2 & 29,1 & 23,3 & 37,5 & 25,7 \\
\hline & Ni buena ni mala & 37,5 & 44,4 & 43,6 & 48,3 & 32,1 & 42,6 \\
\hline & Mala & 17,5 & 27,8 & 20,0 & 21,7 & 19,6 & 22,4 \\
\hline & Muy mala & 3,8 & 11,8 & 7,3 & 5,8 & 7,1 & 7,7 \\
\hline
\end{tabular}

Fuente: Elaboración propia.

Los resultados globales relativos al índice de percepción sobre las relaciones entre la población reclusa encuestada y los funcionarios están 
representados en la Tabla IX y en el Gráfico 3. En éste - al igual que en los gráficos 4 y 5 infra - se han simplificado los resultados mediante la agrupación como "percepción positiva» de los resultados «buena» y «muy buena» y como «percepción negativa» de los resultados «mala» y «muy mala», a fin de reforzar la claridad de la representación visual. En él se aprecia que el 56,0\% está agrupado en las categorías de respuesta positivas (muy buenas y buenas), mientras que tan sólo el 14,3\% del índice se posicionan en las categorías negativas (mala y muy mala).

\section{Gráfico 3. Índice de percepción sobre las relaciones entre internos y funcionarios}
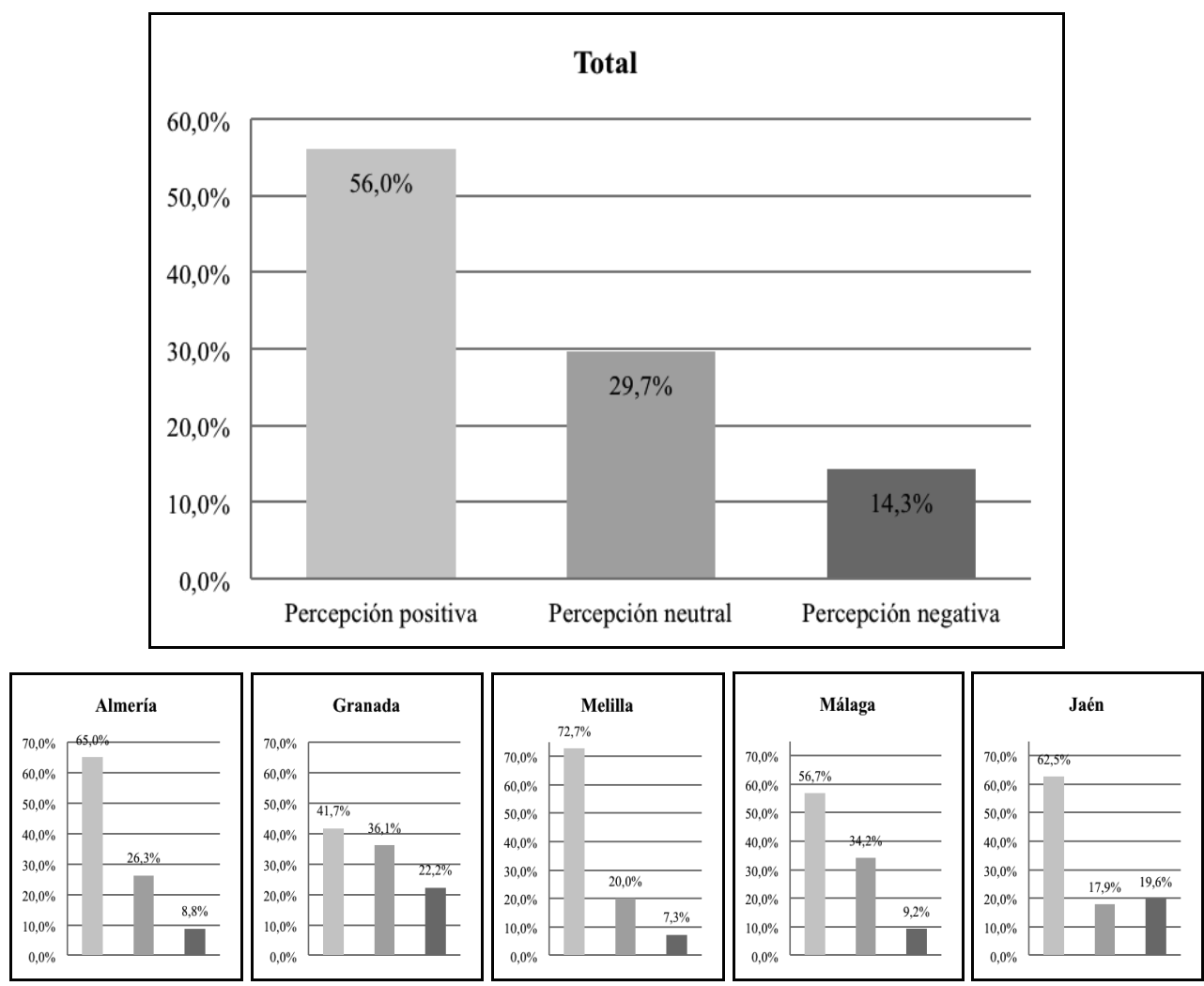

El índice de percepción sobre las relaciones entre internos y funcionarios arrojó unos resultados esencialmente similares en los 5 centros analizados. De esta forma, los internos del centro penitenciario almeriense se posicionaban de forma mayoritaria en las categorías muy buena $(15,0 \%)$ y buena (50,0\%), con una suma del 65,0\% (véase también el Gráfico 3). Algo similar, bien que con obvios matices, ocurría en los centros de Granada con el $41,7 \%$ de los encuestados distribuidos en las mismas catego- 
rías, Melilla con el 72,7\%, Málaga con el 56,7\% y Jaén con un 62,5\%. En el lado opuesto, las categorías negativas son minoritarias, con un máximo en Granada, donde el 22,3\% acumulado considera las relaciones con los funcionarios malas o muy malas. De forma específica, puede destacarse como dato llamativo el $0,0 \%$ de los reclusos que, una vez construido el índice, habrían calificado sus relaciones con el personal del centro como muy malas en el establecimiento penitenciario malagueño.

En cuanto al total de los cinco centros, el índice de percepción sobre las relaciones entre internos (Tabla IX y Gráfico 4) resultó seguir la distribución del índice anterior, acumulando un $42,9 \%$ de la muestra que consideran sus relaciones con otros internos buenas $(35,8 \%)$ o muy buenas $(7,0 \%)$. Los presos cuya percepción sobre las susodichas relaciones es mala o muy mala solo representan el $12,3 \%$ de la muestra.

\section{Gráfico 4. Índice de percepción sobre las relaciones entre internos}
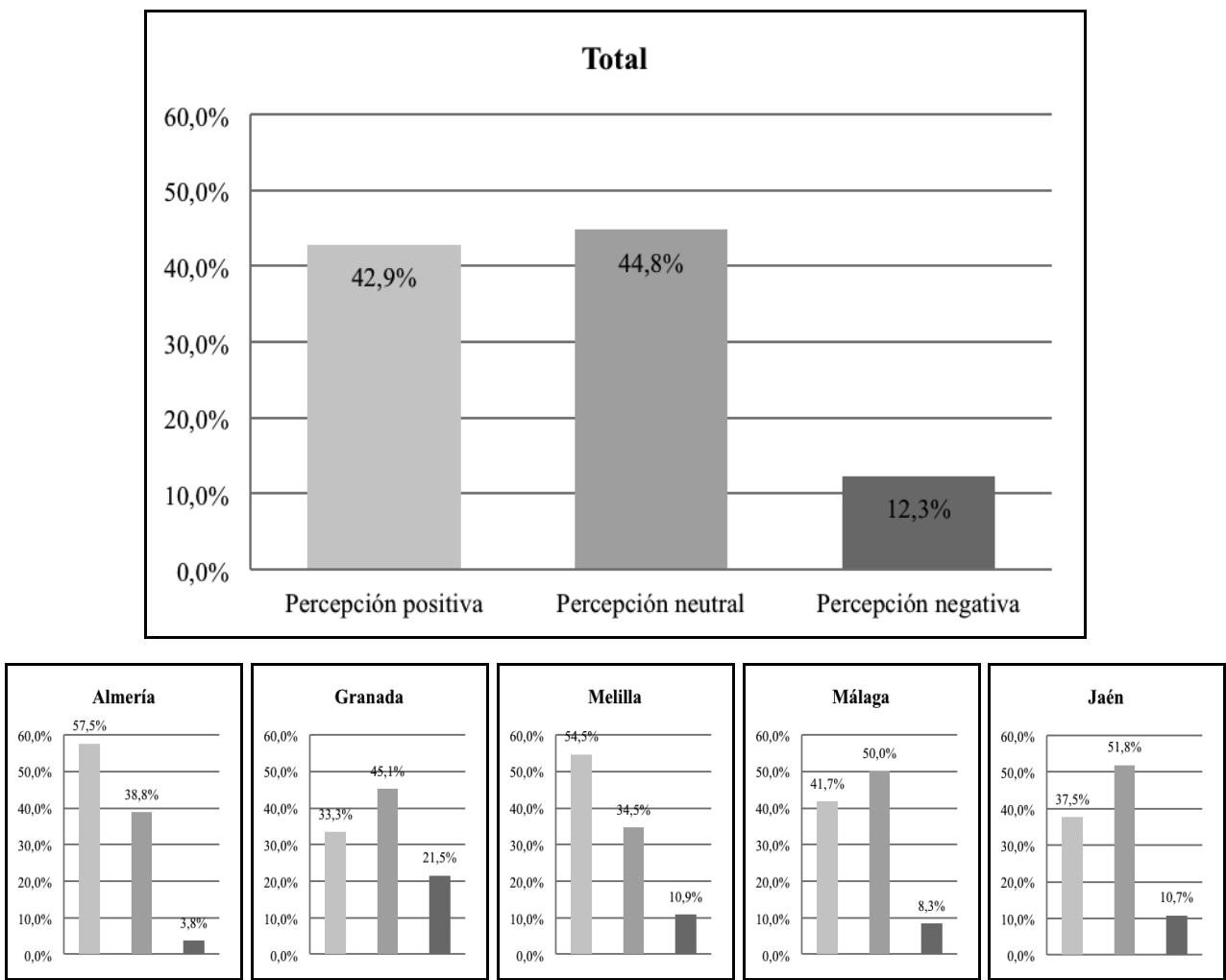

El índice de percepción sobre las relaciones entre internos también sigue la tendencia del índice precedente, si bien la categoría «ni buena ni mala» concentraba porcentajes muy altos, llegando a alcanzar un 50,0\% 
en Málaga y un 51,8\% en Jaén. Las categorías positivas (buena y muy buena) acumulan un 57,5\% en el centro de Almería, un 33,3\% en Granada, 54,5\% en Melilla, 41,7\% en Málaga y un 37,5\% en el centro jiennense (Gráfico 4). Las categorías opuestas (mala y muy mala) obtuvieron porcentajes que no llegaron a superar el $25 \%$ en ninguno de los centros encuestados; de hecho la categoría «muy mala» alcanzó porcentajes bajos, como muestra un 0,0\% en Almería o el 0,8\% obtenido en Málaga.

El total revela que las distribuciones porcentuales que atañen al índice de percepción sobre el ambiente en prisión y sus repercusiones en la resocialización se apartan de las de los otros dos índices. En este caso, el $30,1 \%$ de los presos se posicionaban en una percepción negativa (mala y muy mala) frente al 27,2\% que se posicionaban en una percepción positiva (Tabla IX y Gráfico 5).

\section{Gráfico 5. Índice de percepción sobre el ambiente en prisión y sus repercusiones en la resocialización}
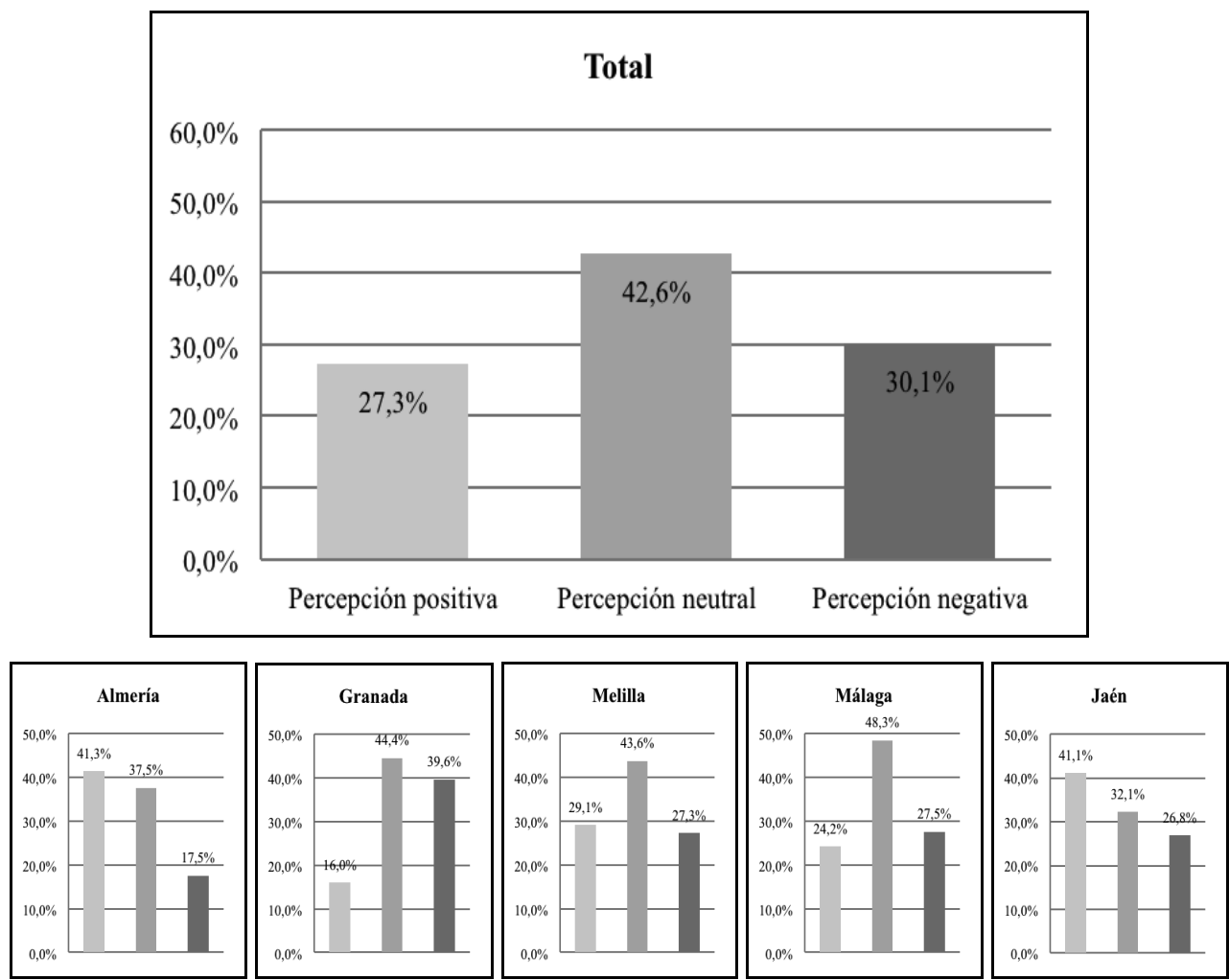

Los resultados obtenidos en el cruce entre el centro penitenciario y el índice de percepción sobre el ambiente en prisión y sus repercusiones en 
la resocialización tampoco mostraron la cuasihomogeneidad obtenida en los dos índices anteriores. El 41,3\% de los reclusos encuestados del centro penitenciario de Almería (Gráfico 5) tenían una percepción buena sobre el ambiente en prisión y sus repercusiones en la resocialización; ello es muy cercano al dato de Jaén, donde un $41,1 \%$ de los reclusos también lo percibían como bueno $(37,5 \%)$ y muy bueno $(3,6 \%)$. Por el contrario, los porcentajes más altos obtenidos en las categorías negativas se dieron en el centro penitenciario de Granada $(39,6 \%$ ) y en la prisión de Melilla $(27,3 \%)$. Como datos extraordinarios aparecidos en este índice, se encontró que el resultado atribuido por la construcción del propio índice a la calificación por los reclusos como muy buena de su percepción sobre el ambiente carcelario y la repercusión en su resocialización fue del 0,0\% en los centros penitenciarios de Almería y de Melilla.

\subsubsection{Análisis de chi cuadrado y Eta}

Para concluir el análisis y la exposición de los resultados, se han aplicado las pruebas $\chi^{2}$ y Eta al cruce de los índices con el centro penitenciario $\left(\right.$ Tabla $X$ ). El estadístico $\chi^{2}$ mostró la existencia de diferencias significativas entre el centro penitenciario y el índice de percepción sobre las relaciones entre internos y funcionarios (n.s. 0,000); entre el centro y el índice de percepción sobre las relaciones entre internos (n.s. 0,001); y entre el centro penitenciario y el índice de percepción sobre el ambiente en prisión y sus repercusiones en la resocialización (n.s. 0,002).

\section{Tabla X: Medias de asociación para los índices de percepción y centro penitenciario}

\begin{tabular}{|c|c|c|c|c|}
\hline & \multicolumn{2}{|c|}{ Pruebas de chi-cuadrado } & \multirow{2}{*}{\multicolumn{2}{|c|}{$\frac{\text { Medidas direccionales }}{\text { Eta (Nominal por Escala) }}$}} \\
\hline & $\begin{array}{l}\text { Chi-cuadrado } \\
\text { de Pearson }\end{array}$ & $\begin{array}{l}\text { Sig. asintótica } \\
\text { (bilateral) }\end{array}$ & & \\
\hline \multirow{2}{*}{$\begin{array}{l}\text { Índice de percepción } \\
\text { sobre las relaciones } \\
\text { entre internos y } \\
\text { funcionarios }\end{array}$} & \multirow{2}{*}{43,801} & \multirow{2}{*}{,000 } & $\begin{array}{l}\text { Índice relaciones } \\
\text { internos-funcionarios }\end{array}$ & ,239 \\
\hline & & & $\begin{array}{l}\text { Centro penitenciario } \\
\text { dependiente }\end{array}$ & ,093 \\
\hline \multirow{2}{*}{$\begin{array}{l}\text { Índice de percepción } \\
\text { sobre las relaciones } \\
\text { entre internos }\end{array}$} & \multirow{2}{*}{41,15} & \multirow{2}{*}{,001 } & \begin{tabular}{|l|} 
Índice relaciones \\
internos-internos
\end{tabular} &, 217 \\
\hline & & & $\begin{array}{l}\text { Centro penitenciario } \\
\text { dependiente }\end{array}$ & ,091 \\
\hline \multirow{2}{*}{$\begin{array}{l}\text { Índice de percepción } \\
\text { sobre el ambiente } \\
\text { en prisión y sus } \\
\text { repercusiones en la } \\
\text { resocialización }\end{array}$} & \multirow[t]{2}{*}{36,64} & \multirow[t]{2}{*}{,002 } & $\begin{array}{l}\text { Índice ambiente } \\
\text { en prisión y } \\
\text { resocialización }\end{array}$ & 200 \\
\hline & & & $\begin{array}{l}\text { Centro penitenciario } \\
\text { dependiente }\end{array}$ &, 037 \\
\hline
\end{tabular}

Fuente: Elaboración propia. 
Finalmente, el coeficiente Eta mostró unos resultados en consonancia con los conseguidos por este mismo estadístico en sus anteriores aplicaciones; pues, si bien corroboraba la existencia de diferencias entre las variables comentadas, esta relación resultó no ser muy intensa -no se llegó a superar el 0,3 en ningún caso- aun habiéndose mostrado que las relaciones eran significativas.

\section{Conclusiones}

La investigación desarrollada tiene un objetivo primario que puede en cierto sentido considerarse autocumplido por definición. Esto es, ante el limitado número de estudios llevados a cabo en España acerca de la calidad de vida penitenciaria, y mucho menos con resultados comparativos de diferentes prisiones, la mera realización del presente trabajo de campo, seguido del análisis estadístico y la presentación de los resultados conlleva implícitamente una aportación, que esperamos suficientemente significativa, para el mejor conocimiento del medio penitenciario y de estado moral de las prisiones en nuestro país. Lo novedoso del estudio que aquí se presenta radica en que los resultados son fruto de la opinión emitida por los internos al cuestionario repartido, y ello a través de un contacto directo entre ellos y los autores del trabajo de investigación, sin barreras físicas o personales de por medio. Como se ha señalado anteriormente, la mayoría de los trabajos que hasta ahora se han realizado en España para valorar el estado de las prisiones se han limitado a enviar cuestionarios a los internos, sin que haya habido por tanto un contacto directo con ellos, impidiéndose así no sólo una percepción de su experiencia personal en prisión, sino también una visión ambiental de las condiciones de vida en un determinado centro penitenciario.

En términos más específicos, la hipótesis de partida era que la reeducación y la reinserción social, elemento fundamental que la propia Constitución Española establece como finalidad de la ejecución de las penas privativas de libertad (art. 25.2), se cumple en líneas generales a partir de los resultados de las encuestas llevadas a cabo en los cinco centros penitenciarios objeto de la muestra, si bien existen diferencias entre los centros. Para ello, dicha hipótesis se ha concretado en tres variables, cada una de las cuales estaba compuesta por cinco afirmaciones previamente seleccionadas del cuestionario respondido por los internos.

Tras el estudio empírico realizado en las cinco prisiones situadas en Andalucía Oriental, se puede afirmar que dicha hipótesis ha sido verificada, bien que únicamente con respecto a las variables relativas a la relación funcionarios-internos e internos-internos. Por el contrario, la tercera variable, sobre el ambiente en prisión, arroja en el análisis de los items de la encuesta concretamente seleccionados para esta variable un resultado general inconclusivo en cuanto a la hipótesis de partida, por 
ausencia de una línea consistente en sentido positivo o negativo común a los diferentes items y a los cinco centros penitenciarios.

Ahora bien, el aspecto más importante a señalar es la diferencia existente entre los cinco centros penitenciarios cuando se valoran las tres variables comentadas. Efectivamente, si se analizan aspectos tales como el apoyo y la amabilidad dispensada a los internos por parte de los funcionarios de prisiones, la presencia o no de conflictos entre internos o bien las condiciones de vida en prisión o la utilidad de los programas de tratamiento, parece claro que las condiciones que presenta algún establecimiento penitenciario para lograr el mandato establecido en el art. 25.2 CE son claramente mejores que las de algunos otros que arrojan resultados más débiles.

Con todo, los resultados que aquí se presentan se refieren únicamente a un conjunto de centros penitenciarios ubicados en una de las 17 comunidades autónomas españolas, más una de las dos ciudades autónomas, por lo que sería conveniente disponer en un futuro de datos empíricos de otros centros ubicados en otras zonas del país para extraer conclusiones generales sobre la calidad de vida en los centros penitenciarios del Reino de España y sus repercusiones en la reeducación y reinserción social de los internos. La versión adaptada del cuestionario MQPL utilizado en el presente trabajo constituye a nuestro juicio una herramienta muy útil para obtener información sobre la calidad de vida en prisión a través del contacto directo con la población penitenciaria, así como para acceder a una imagen fiable de la percepción desde dentro acerca de las condiciones ambientales, materiales y personales de los centros objeto de estudio.

\section{Referencias}

Barquín Sanz, J., Cano Paños M.Á. y Calvo Alba, M.Á. (2016). Percepción de la calidad de vida en prisión por los reclusos en dos centros: Una aproximación en materia de reinserción. En: Morillas, L. (dir.) La pena de prisión entre el expansionismo y el reduccionismo punitivo. Madrid: Dykinson, 459-511.

BECERRA, J. (2012). Las prisiones españolas vistas desde Europa. Un análisis comparado. Revista de Derecho Penal y Criminología, (3. época) 7, 381-406.

Benítez JimÉnez, M.J. (2007). Población penitenciaria: evolución, volumen y características demográficas. En: Cerezo Domínguez, A.I. y García España, E. (ed.). La prisión en España. Una perspectiva criminológica. Granada: Comares, 41-74.

Beyens, K. y Boone, M. (2015). Mixing detention cultures: The BelgianDutch case. En: Drake, D., Earle, R. y Sloan, J. (ed). The Palgrave Handbook of Prison Ethnography (1 $1^{\text {st }}$ Edition), Basingstoke: Palgrave Macmillan, 479-498. https://doi.org/10.1057/9781137403889_26. 
BRANDÁRIZ, J.A. (2015). La evolución del sistema penitenciario español, 1995-2014: Transformaciones de la penalidad y modificación práctica de la realidad penitenciaria. Crítica Penal y Poder, 9, 1-31.

Cabrera Cabrera, P.J. y Ríos Martín, J.C. (1998). Mil voces presas. Madrid: Universidad Pontificia de Comillas.

CID, J. (2008). El incremento de la población reclusa en España entre 1996-2006: Diagnóstico y remedios. Revista Española de Investigación Criminológica, 6, 1-31.

CutiÑo Raya, S. (2015). Algunos datos sobre la realidad del tratamiento en las prisiones españolas. Revista Electrónica de Ciencia Penal y Criminología, 17-11, 1-41.

DíEz RIPOLLÉs, J.L. (2006). La evolución del sistema de penas en España: 1975-2003. Revista Electrónica de Ciencia Penal y Criminología, 08-07, $1-25$.

DiIulio, J.J. (1987). Governing Prisons, London: Free Press.

DÜNKEL, F. (2017). European penology: The rise and fall of prison population rates in Europe in times of migrant crises and terrorism. European Journal of Criminology, 14 (6), 629-653. https://doi. org/10.1177/1477370817733961.

Gallego Díaz, M., Cabrera Cabrera, P.J., Ríos Martín, J.C. y Segovia Bernabé, J.L. (2010). Andar $1 \mathrm{~km}$. en línea recta. La cárcel del siglo XXI que vive el preso, Madrid: Universidad Pontificia de Comillas.

Kruttschnitt, C. y Dirkzwager, A. (2011). Are there still contrasts in tolerance? Imprisonment in the Netherlands and England 20 years later. Punishment\&Society, 13 (3), 283-306. https://doi. org/10.1177/1462474511404333.

Liebling, A. y ARnold, H. (assist.) (2004). Prisons and their Moral Performance. A Study of Values, Quality, and Prison Life, Oxford: Oxford University Press.

Martí BarRachina, M. (2017). El estudio de la calidad de vida en prisión. Una revisión bibliográfica de la investigación en España y principales planteamientos internacionales. InDret, 3/2017, 1-34.

Moos, R.H. (1968). The assessment of the social climates of correctional institutions. Journal of Research in Crime and Delinquency, 5 (2), 174188. https://doi.org/10.1177/002242786800500207.

Rodríguez Menés, J., LarRauri Pijoan. E. y GÜERri FerRández, C. (2018). Percepción de la calidad de vida en prisión. La importancia de una buena organización y un trato digno. Revista Internacional de Sociología, 76(2):e098, 1-20. DOI: 10.3989/ris.2018.76.2.16.159

SPARKS, J.R. y BотTOMS, A.E. (1995). Legitimacy and order in prisons. British Journal of Sociology, 46 (1), 45-62. https://doi. org/10.2307/591622. 
